Revised manuscript

\title{
Long-term diffusion of U(VI) in bentonite: Dependence on density
}

\author{
Claudia Joseph ${ }^{\mathrm{a}, *}$, Jens Mibus ${ }^{\mathrm{b}, 1}$, Paul Trepte ${ }^{\mathrm{b}, 2}$, Christa Müller ${ }^{\mathrm{b}}$, Vinzenz Brendler ${ }^{\mathrm{b}}$, Dan M. \\ Park $^{c}$, Yongqin Jiao ${ }^{c}$, Annie B. Kersting ${ }^{a}$, Mavrik Zavarin ${ }^{\text {a }}$ \\ ${ }^{\text {a }}$ Glenn T. Seaborg Institute $/{ }^{c}$ Biosciences and Biotechnology Division \\ at: Physical \& Life Sciences Directorate, Lawrence Livermore National Laboratory, L-231, P.O. Box 808, Livermore, CA 94550, \\ USA \\ ${ }^{\mathrm{b}}$ Helmholtz-Zentrum Dresden-Rossendorf e.V., Institute of Resource Ecology, P.O. Box 510119, 01314 Dresden, Germany \\ * Corresponding author at: Glenn T. Seaborg Institute, Physical \& Life Sciences Directorate, Lawrence Livermore National \\ Laboratory, L-231, P.O. Box 808, Livermore, CA 94550, USA, phone: +1 925 422-1680, fax: +1 925 423-9719. \\ E-mail address: joseph20@1lnl.gov
}

${ }^{1}$ Present address: Nagra, Hardstrasse 73, CH-5430 Wettingen, Switzerland

${ }^{2}$ Present address: LSI Sachsen GmbH \& Co. KG, BioInnovationsZentrum Dresden, Tatzberg 47, 01307 Dresden, Germany

(C) 2016. This manuscript version is made available under the Elsevier user license http://www.elsevier.com/open-access/userlicense/1.0/ 


\begin{abstract}
As a contribution to the safety assessment of nuclear waste repositories, U(VI) diffusion through the potential buffer material MX-80 bentonite was investigated at three clay dry densities over six years. Synthetic MX-80 model pore water was used as background electrolyte. Speciation calculations showed that $\mathrm{Ca}_{2} \mathrm{UO}_{2}\left(\mathrm{CO}_{3}\right)_{3}(\mathrm{aq})$ was the main $\mathrm{U}(\mathrm{VI})$ species. The in- and outdiffusion of U(VI) was investigated separately. U(VI) diffused about $3 \mathrm{~mm}, 1.5 \mathrm{~mm}$, and $1 \mathrm{~mm}$ into the clay plug at $\rho=1.3,1.6$, and $1.9 \mathrm{~g} / \mathrm{cm}^{3}$, respectively. No through-diffusion of the U(VI) tracer was observed. However, leaching of natural uranium contained in the clay occurred and uranium was detected in all receiving reservoirs. As expected, the effective and apparent diffusion coefficients, $D_{\mathrm{e}}$ and $D_{\mathrm{a}}$, decreased with increasing dry density. The $D_{\mathrm{a}}$ values for the out-diffusion of natural U(VI) were in good agreement with previously determined values. Surprisingly, $D_{\text {a }}$ values for the in-diffusion of U(VI) were about two orders of magnitude lower than values obtained in short-term in-diffusion experiments reported in the literature. Some potential reasons for this behavior that were evaluated are changes of the U(VI) speciation within the clay (precipitation, reduction) or changes of the clay porosity and pore connectivity with time. By applying Archie's law and the extended Archie's law, it was estimated that a significantly smaller effective porosity must be present for the long-term in-diffusion of U(VI). The results suggest that long-term studies of key transport phenomena may reveal additional processes that can directly impact long-term repository safety assessments.
\end{abstract}

Keywords: nuclear waste repository, MX-80, clay, uranium, speciation, extended Archie's law 


\section{Introduction}

High-level nuclear waste (HLW), mainly resulting from nuclear weapons production and nuclear power plants, is defined as that part of nuclear waste that is highly radioactive $\left(5 \times 10^{16}\right.$ $\left.5 \times 10^{17} \mathrm{~Bq} / \mathrm{m}^{3}\right)$ and releases high decay heat $\left(2-20 \mathrm{~kW} / \mathrm{m}^{3}\right)$ (IAEA, 1994). It consists of spent nuclear fuel (predominantly uranium) and, in some countries, of waste materials formed during the reprocessing of the fuel. It presents a highly chemo- and radiotoxic risk to the environment. The main strategy of HLW management is to place the waste in engineered containers and dispose of it safely in deep geological formations such as salt, crystalline rock, or clay-rich rock. Radionuclide entry into the biosphere needs to be limited for very long time periods (e.g., one million years in regulatory requirements in several nations (OECD/NEA, 2009)). Irrespective of the chosen host rock, in many of the nuclear waste repository designs currently under development, the clay-rich rock bentonite is proposed as material used to backfill the excavated cavities after disposal of the waste containers. Bentonite will acquire different bulk densities depending on the design of confinement (Keto et al., 2007). Typically, bentonite dry bulk densities range from 1.5 to $1.8 \mathrm{~g} / \mathrm{cm}^{3}$, which are high enough to suppress microbial activity in the repository near field (Stroes-Gascoyne, 2011).

In safety assessment calculations, the release of radionuclides after the rupture of the waste containers and the radionuclides' potential migration through the buffer material and the host rock into the biosphere must be investigated. For this purpose, the respective retardation factors of the radionuclides migrating through and interacting with different barriers need to be determined under environmentally relevant conditions. Waste-released radionuclides can be retarded by the surrounding barriers (e.g., waste container, backfill material, host rock) in several ways such as sorption, surface precipitation, molecular diffusion, or a combination of these processes. For instance, the natural clay-rich rock Opalinus Clay, which is discussed as potential host rock for a nuclear waste repository in Switzerland, has been studied by batch sorption (Joseph et al., 2011; Wu et al., 2009) and diffusion experiments (Appelo et al., 2010; Joseph et al., 2013b; Wu et al., 2009).

Many studies focus on radionuclide diffusion through bentonite since this barrier interacts with the migrating radionuclides before reaching the host rock. In particular, the influence of bentonite density on the radionuclide diffusion has been studied for tritiated water (HTO) (Brockmann, 2006; Sato et al., 1992), ${ }^{90} \mathrm{Sr}^{2+}$ (Kim et al., 1993; Sato et al., 1992), ${ }^{99} \mathrm{TcO}_{4}^{-}$(Sato et 
al., 1992), ${ }^{129} \mathrm{I}^{-}$(Sato et al., 1992), ${ }^{137} \mathrm{Cs}^{+}$(Brockmann, 2006; Kim et al., 1993; Sato et al., 1992), ${ }^{36} \mathrm{Cl}^{-}$(Kim et al., 1993; Van Loon et al., 2007b), ${ }^{237} \mathrm{~Np}(\mathrm{~V})$ (Kozai et al., 2001; Sato et al., 1992), and ${ }^{241} \mathrm{Am}(\mathrm{III})$ (Sato et al., 1992). The general observation of all studies is that the effective diffusion coefficient, $D_{\mathrm{e}}$, decreases with increasing density.

Uranium, in particular the isotopes ${ }^{238} \mathrm{U}$ (half-life, $t_{1 / 2}=4.468 \times 10^{9}$ a) and ${ }^{235} \mathrm{U}$ $\left(t_{1 / 2}=7.038 \times 10^{8} \mathrm{a}\right)$, represents the main fraction of spent nuclear fuel rods (about $95 \%$ (Volkmer, 2007)) and consequently, constitutes the majority of HLW. It accounts for only $\sim 0.005 \%$ of the initial total radiotoxicity of the spent nuclear fuel (OECD/NEA, 2006). However, after about one million years and due to the decay of plutonium and the minor actinides, the uranium contribution to the total radiotoxicity increases to about $30 \%$. Moreover, the chemotoxicity of ${ }^{238} \mathrm{U}$ is about two orders of magnitude larger than its radiotoxicity (Bleise et al., 2003). In general, uranium is stored in the oxidation state IV in the form of $\mathrm{UO}_{2}$, which is insoluble and immobile under most repository-relevant conditions. However, several oxidation processes can occur whereby U(IV) can be partly transformed to U(VI) (Bruno et al., 2004; Thoenen, 2014), resulting in more mobile species.

Table 1: Literature selection of experimental conditions ( $t$ : time; $\rho$ : dry bulk density) and corresponding diffusion parameters ( $D_{\mathrm{a}}$ : apparent diffusion coefficient; $K_{\mathrm{d}}$ : distribution coefficient), which have been determined for uranium diffusion through compacted bentonite/montmorillonite.

\begin{tabular}{lllll}
\hline $\boldsymbol{t} / \mathbf{d a y s}$ & $\boldsymbol{\rho} / \mathbf{g} / \mathbf{c m}^{3}$ & $\boldsymbol{D}_{\mathbf{a}} / \mathbf{~ m}^{2} / \mathbf{s}$ & $\boldsymbol{K}_{\mathbf{d}} / \mathbf{m}^{3} / \mathbf{k g}$ & Reference \\
\hline 62 & 2.0 & $3.4 \times 10^{-12} ; 6.4 \times 10^{-13} ;$ & 0.093 & $\underline{\text { Torstenfelt and Allard (1986) }}$ \\
& & $2.7 \times 10^{-13}$ & & \\
$48 ; 85$ & 0.9 & $1.16-2.3 \times 10^{-12}$ & $0.047-0.310$ & $\underline{\text { Wang et al. (2005) }}$ \\
90 & 1.6 & $3 \times 10^{-15}-6.6 \times 10^{-14}$ & $0.0013-0.0023$ & $\underline{\text { Glaus and Van Loon (2012) }}$ \\
$29-121$ & $0.8-1.8$ & $3.7 \times 10^{-12}-3.1 \times 10^{-14}$ & $0.01-0.1$ & $\underline{\text { Idemitsu et al. (1996) }}$ \\
279 & 1.65 & $4 \times 10^{-14}-1 \times 10^{-13}$ & $0.006-0.021$ & $\underline{\text { Garcia-Gutierrez et al. (2004) }}$ \\
$90-2220$ & 2.0 & $1.9 \times 10^{-13}-1.6 \times 10^{-14}$ & - & $\underline{\text { Ramebäck et al. (1998) }}$ \\
\hline
\end{tabular}

Table 1 lists studies that have investigated uranium diffusion through bentonite. The majority of experiments to date have been performed for less than one year, except the study of 
Ramebäck et al. (1998), where the uranium release from spent $\mathrm{UO}_{2}$ fuel and its migration through compacted MX-80 bentonite was investigated for 2,220 days. Models used in safety assessment must extrapolate radionuclide transport to the time scale of thousands of years. This raises the question of whether the values obtained in short-term experiments are also valid for longer time periods or if other factors may influence the diffusion with time. Some of these studies have been performed at lower bentonite densities than are expected in a repository (Wang et al., 2005). Others have used simple systems with background electrolytes such as water (Garcia-Gutierrez et al., 2004; Idemitsu et al., 1996) or $\mathrm{NaClO}_{4}$ (Wang et al., 2005). While these studies provide valuable diffusion information, conditions more representative of a repository near-field (i.e., higher dry densities, complex salt solution, longer timescales) also need to be investigated.

In the present study, the diffusion of HTO and U(VI) through compacted MX-80 bentonite was investigated across a range of dry densities $\left(\rho=1.3,1.6,1.9 \mathrm{~g} / \mathrm{cm}^{3}\right)$ at room temperature under ambient conditions. Synthetic MX-80 model pore water (Van Loon et al., 2007a) was used as background electrolyte. HTO diffusion experiments were used to determine values for the effective porosity, $\varepsilon_{\text {eff }}[-]$. U(VI) diffusion experiments were conducted for six years to evaluate long-term diffusion behavior. The following two hypotheses were tested: (1) Increasing bentonite dry density will lead to a decrease of the U(VI) effective diffusion coefficient and (2) long-term diffusion experiments will reveal additional retardation processes that limit U(VI) migration. The results contribute to the safety assessment of nuclear waste repositories for HLW. The modeling codes CrunchFlow2011 (Steefel, 2011) and COMSOL Multiphysics® 5.0 (COMSOL, 2014) were applied to determine the diffusion parameters ( $\varepsilon_{\text {eff }}$, effective diffusion coefficient, $D_{\mathrm{e}}\left[\mathrm{m}^{2} / \mathrm{s}\right]$; distribution coefficient, $K_{\mathrm{d}}\left[\mathrm{m}^{3} / \mathrm{kg}\right]$; apparent diffusion coefficient, $D_{\mathrm{a}}$ $\left[\mathrm{m}^{2} / \mathrm{s}\right]$ ) based on the collected experimental data. The relation between the resulting fit values of $\varepsilon_{\text {eff }}(\mathrm{HTO}, \mathrm{U}(\mathrm{VI}))$ and $D_{\mathrm{e}}(\mathrm{HTO}, \mathrm{U}(\mathrm{VI}))$ were interpreted according to Archie's law (Boving and Grathwohl, 2001) and the extended Archie's law (Van Loon and Mibus, 2015). 


\section{Material and methods}

\subsection{Solid phase and solutions}

In the diffusion experiments, Na-bentonite MX-80 from Wyoming, USA was used and provided as granulate by Süd-Chemie AG (Munich, Germany). It consists of $\sim 90 \%$ montmorillonite, $4 \%$ quartz, $2 \%$ muscovite, $2 \%$ calcite, $<2 \%$ cristobalite, and $<1 \%$ pyrite (Herbert and Moog, 2002). The uranium content was $13 \pm 0.1 \mu \mathrm{g} / \mathrm{g}$, determined by inductively coupled plasma-mass spectrometry (ICP-MS; mod. Thermo Scientific ${ }^{\mathrm{TM}}$ iCAPTM $^{\mathrm{T}} \mathrm{Q}$, Thermo Electron Corp., Waltham, MA, USA) after digestion of MX-80 samples with $\mathrm{HNO}_{3}$ (GR ACS, EMD Millipore, Billerica, MA, USA), HCl (ACS, VWR Scientific Products, Radnor, PA, USA), and HF (ultra high purity, BDH Aristar ${ }^{\circledR}$ Ultra, Merck Ltd., Poole Dorset, UK) on a hot plate (mod. vwr 300, VWR Scientific Products).

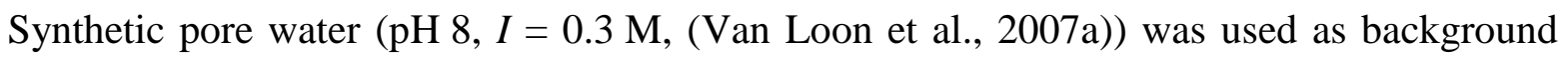
electrolyte in the diffusion experiments. Its composition was calculated at the Paul Scherrer Institute based on the inventory of the soluble salts of the MX-80, the cation loading of the surface, $\varepsilon_{\mathrm{eff}}\left(\mathrm{Cl}^{-}\right)$, and several saturation phases in the MX-80 (Bradbury and Baeyens, 2003b). In this study, three dry bulk densities were investigated: $1.3,1.6$, and $1.9 \mathrm{~g} / \mathrm{cm}^{3}$. The modeled compositions of the respective pore waters with their ionic strength, $I$, are summarized in Table 2. The solutions were prepared under ambient conditions in Milli-Q water (18 M $\Omega$; mod. Milli-RO/Milli-Q-System, Millipore, Schwalbach, Germany). The $\mathrm{pH}$ was measured using a laboratory pH meter (mod. inoLab pH 720, WTW, Weilheim, Germany) with a BlueLine $16 \mathrm{pH}$ microelectrode (SI Analytics, Mainz, Germany), calibrated using standard buffers (WTW) at $\mathrm{pH} 7$ and 9, and adjusted to $\mathrm{pH} 8$ in the solutions using diluted $\mathrm{NaOH}$ (p.a., Merck, Darmstadt, Germany) and $\mathrm{HCl}$ (p.a., Merck).

An HTO solution (1.2 MBq/mL; Eckert \& Ziegler, Valencia, CA, USA) and a depleted $\mathrm{U}(\mathrm{VI})$ solution in $0.005 \mathrm{M} \mathrm{HCl}\left(5 \times 10^{-4} \mathrm{M} \mathrm{UO}_{2} \mathrm{Cl}_{2}\right)$ were used as stock solutions to adjust the initial concentrations of $c_{0}(\mathrm{HTO})=500 \mathrm{~Bq} / \mathrm{mL}\left(=2.2 \times 10^{-10} \mathrm{M}\right)$ and $c_{0}(\mathrm{U}(\mathrm{VI}))=1 \times 10^{-6} \mathrm{M}$ in the source reservoir solutions for the respective diffusion experiments. 
Table 2: Composition of the model pore water as a function of dry bulk density (Van Loon et al., 2007a).

\begin{tabular}{lccc}
\hline $\boldsymbol{\rho} / \mathbf{g} / \mathbf{c m}^{3}$ & $\mathbf{1 . 3}$ & $\mathbf{1 . 6}$ & $\mathbf{1 . 9}$ \\
$\boldsymbol{\varepsilon}_{\mathrm{eff}}(\mathbf{C l})$ & $\mathbf{0 . 1 2 2}$ & $\mathbf{0 . 0 4 4}$ & $\mathbf{0 . 0 1 9}$ \\
\hline$p\left(\mathrm{CO}_{2}\right) /$ bar & -3.42 & -3.47 & -3.65 \\
$\mathrm{Na} / \mathrm{M}$ & $1.83 \times 10^{-1}$ & $2.07 \times 10^{-1}$ & $2.54 \times 10^{-1}$ \\
$\mathrm{~K} / \mathrm{M}$ & $2.7 \times 10^{-3}$ & $3.1 \times 10^{-3}$ & $3.7 \times 10^{-3}$ \\
$\mathrm{Mg} / \mathrm{M}$ & $1.0 \times 10^{-2}$ & $1.2 \times 10^{-2}$ & $1.5 \times 10^{-2}$ \\
$\mathrm{Ca} / \mathrm{M}$ & $9.2 \times 10^{-3}$ & $9.8 \times 10^{-3}$ & $1.2 \times 10^{-2}$ \\
$\mathrm{Sr} / \mathrm{M}$ & $8.1 \times 10^{-5}$ & $8.6 \times 10^{-5}$ & $1.1 \times 10^{-4}$ \\
$\mathrm{Cl} / \mathrm{M}$ & $1.81 \times 10^{-2}$ & $6.18 \times 10^{-2}$ & $1.7 \times 10^{-2}$ \\
$\mathrm{SO} 4 / \mathrm{M}$ & $1.02 \times 10^{-1}$ & $9.5 \times 10^{-2}$ & $7.1 \times 10^{-2}$ \\
$\mathrm{C}_{\mathrm{inorg}} / \mathrm{M}$ & $8.9 \times 10^{-4}$ & $8.0 \times 10^{-4}$ & $5.5 \times 10^{-4}$ \\
$\mathrm{~F} / \mathrm{M}$ & $2.2 \times 10^{-4}$ & $2.2 \times 10^{-4}$ & $1.9 \times 10^{-4}$ \\
$\mathrm{Si} / \mathrm{M}$ & $1.8 \times 10^{-4}$ & $1.8 \times 10^{-4}$ & $1.8 \times 10^{-4}$ \\
\hline $\boldsymbol{I} / \mathrm{M}$ & $\mathbf{0 . 2 6}$ & $\mathbf{0 . 2 9}$ & $\mathbf{0 . 3 3}$ \\
\hline
\end{tabular}

\subsection{Experimental set-up}

Table 3: Dimensions of the filters and the MX-80 samples.

\begin{tabular}{lll}
\hline & Parameter & Value \\
\hline Filters & Length & $1.55 \times 10^{-3} \mathrm{~m}$ \\
& Diameter & $25.4 \times 10^{-3} \mathrm{~m}$ \\
MX-80 & Length & $5.3 \times 10^{-3} \mathrm{~m}$ \\
& Diameter & $25.7 \times 10^{-3} \mathrm{~m}$ \\
& Cross-sectional area & $5.19 \times 10^{-4} \mathrm{~m}^{2}$ \\
\hline
\end{tabular}

High-grade stainless steel diffusion cells (design has been described in detail in Van Loon et al. (2003)) were used in the diffusion experiments to resist the high swelling pressure of the MX- 
80. In total, four diffusion cells were filled with MX-80, one diffusion cell for each dry density studied $\left(1.3,1.6,1.9 \mathrm{~g} / \mathrm{cm}^{3}\right)$, and one blank cell $\left(1.6 \mathrm{~g} / \mathrm{cm}^{3}\right)$ to monitor the fraction of natural uranium leached out from the MX-80 by contact with the background electrolyte. The required amount of MX-80 was compacted in a cylindrical sample holder between two stainless steel filter plates (316L, pore diameter: $0.01 \mathrm{~mm}$; MOTT industrial division, Farmington, USA). The dimensions of the MX-80 samples and filters are shown in Table 3. The diffusion cells were closed by tightening the screws at the diffusion cell end plates. To compress the MX-80 to dry densities of 1.6 and $1.9 \mathrm{~g} / \mathrm{cm}^{3}$ in the predefined volume of the sample holder, a uniaxial pressure testing machine (Amsler Prüfsysteme AG, Neftenbach, Switzerland) with a constant tension rate of $1 \mathrm{MPa} / \mathrm{min}$ was used. The cells containing MX-80 at dry densities of 1.3 and $1.6 \mathrm{~g} / \mathrm{cm}^{3}$ were equipped with a miniature ring load sensor (mod. 8438, Burster Präzisionsmesstechnik GmbH \& Co. KG, Gernsbach, Germany) to measure the swelling pressure in the compacted MX-80. Previous measurements indicated that at $1.9 \mathrm{~g} / \mathrm{cm}^{3}$, the load was too high for load measurements (Brockmann, 2006). Thus, the $1.9 \mathrm{~g} / \mathrm{cm}^{3}$ diffusion cell was not equipped with a ring load sensor. The measured signal of the load cells was converted to millivolts by a one-channel analog input/output module (mod. ADAM 4016, Advantech Corporation, Taipei, Taiwan). Prior to filling with MX-80, calibration curves for the load cells were recorded up to a pressure of $30 \mathrm{MPa}$. For this step, the empty diffusion cells were filled with water using a high-performance liquid chromatography (HPLC) pump (mod. K-501, Knauer, Berlin, Germany) and a flow rate of $0.05 \mathrm{~mL} / \mathrm{min}$.

All experiments were performed under ambient conditions at room temperature. Initially, the respective synthetic pore water was pumped through the confined MX-80 samples with a stepwise increase of the hydraulic pressure (Appendix Table A.1) provided by the HPLC pump with a flow rate of $0.05 \mathrm{~mL} / \mathrm{min}$. After breakthrough of the pore water at the opposite end-plate, the percolation was continued until several pore volumes had been exchanged. Then, the HPLC pump was disconnected and the diffusion cells were coupled with a peristaltic pump (mod. Ecoline, Ismatec, IDEX Health \& Science, Glattbrugg, Switzerland) and a source and receiving reservoir, respectively, filled with the appropriate synthetic pore water. This experimental set-up has been described previously (Brockmann, 2006; Trepte, 2004). The associated load cells measured the swelling pressure of the MX-80 samples as a function of time during this saturation process. Once equilibrium saturation was achieved, the solutions in the source and receiving 
reservoirs were replaced; the new source reservoir solutions contained a radioactive tracer and the receiving reservoir solutions were tracer-free. Initially, HTO through- and out-diffusion experiments were performed as described by Brockmann (2006) in order to determine $\varepsilon_{\text {eff }}$ of MX-80 as a function of dry density. Subsequently, the U(VI) diffusion experiment was performed. During the duration of the experiments, the $\mathrm{pH}$ value in the reservoirs was not adjusted.

In the case of the HTO diffusion experiments, the source and receiving reservoir solutions passing the respective end plates of the diffusion cells were collected in separate reservoirs to prevent tracer solutions from recirculating. The receiving reservoir solutions were regularly exchanged and analyzed. In the case of the U(VI) diffusion experiments, both the source and receiving reservoir solutions were recirculated (Fig. 1) and their U(VI) concentration was regularly analyzed. The receiving reservoir solutions were replaced by fresh solution when their $\mathrm{U}(\mathrm{VI})$ concentration exceeded $1 \%$ of the initial $\mathrm{U}(\mathrm{VI})$ concentration in the source reservoir.

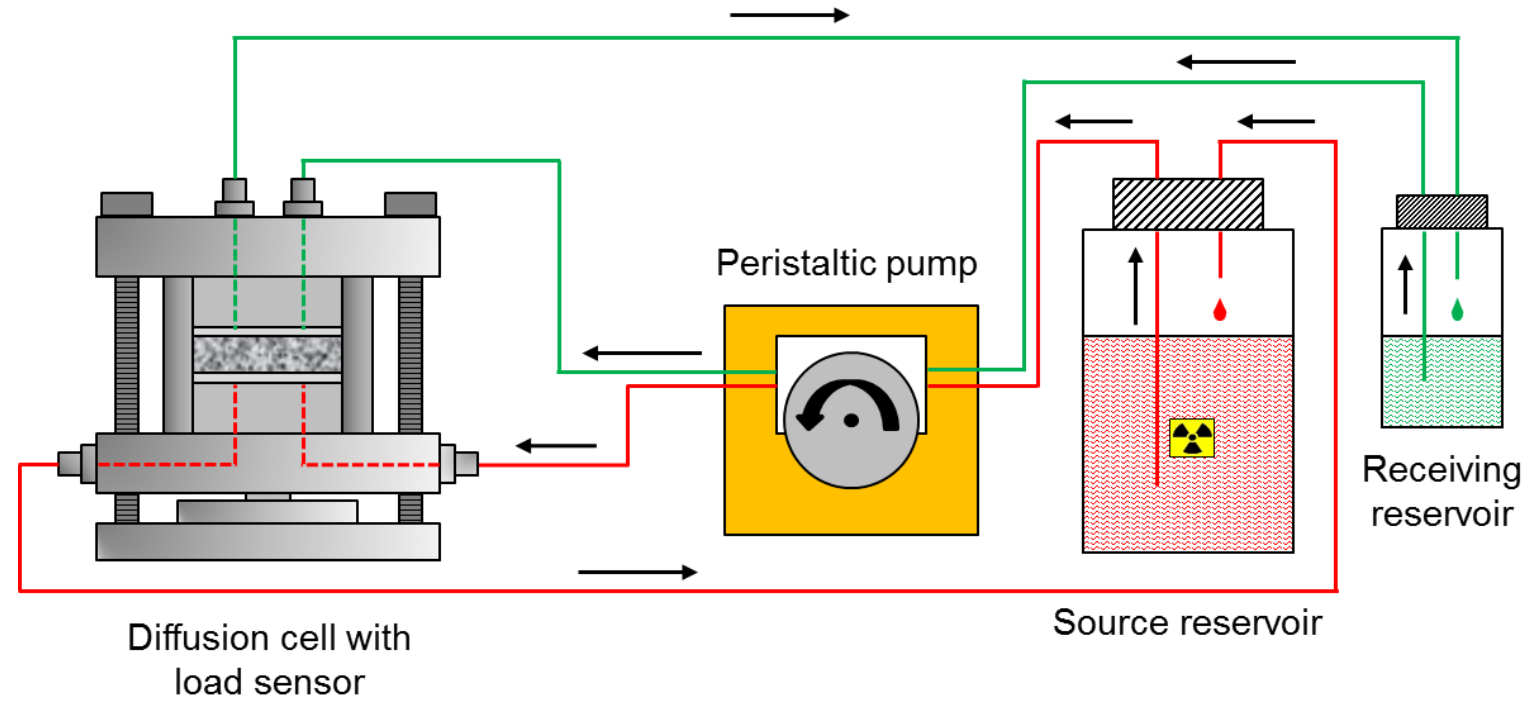

Fig. 1: Experimental set-up for the U(VI) diffusion experiment with compacted bentonite.

\subsection{Characterization of the reservoir solutions}

The composition of the solutions was analyzed with ICP-MS (mod. ELAN 6000, Perkin Elmer, Boston, USA), atomic absorption spectroscopy (AAS; mod. AAS-4100, Perkin Elmer), and ion chromatography (IC; mod. IC separation center 733, Metrohm, Herisau, Switzerland). The total inorganic carbon content was measured using a multi N/C 2100 analyzer (Analytik 
Jena, Jena, Germany) as the difference between the total carbon (TC) and total organic carbon (TOC). The HTO activity was determined by liquid scintillation counting (LSC; mod. 1414 WIN Spectral Low-Level $\alpha / \beta$, Perkin Elmer Wallac GmbH, Freiburg, Germany) using Ultima Gold ${ }^{\mathrm{TM}}$ (Perkin Elmer) as scintillation cocktail. The $\mathrm{U}(\mathrm{VI})$ concentration in the source and receiving reservoirs as well as in the extracts was measured with ICP-MS. All concentration values were decay-corrected.

To interpret the diffusion results, the dominant $\mathrm{U}(\mathrm{VI})$ species in solution must be determined. Based on the composition of the source reservoir solutions, the U(VI) speciation was calculated using "The Geochemist's Workbench ${ }^{\circledR}$ 8.0" speciation code (Bethke and Yeakel, 2010) and the thermodynamic data compiled in Guillaumont et al. (2003) including the data for the alkaline earth tricarbonato complexes with U(VI) (Bernhard et al., 2001; Dong and Brooks, 2006; Lee et al., 2015).

At the end of the diffusion experiment, the reservoir solutions were filtered $(0.45-\mu \mathrm{m}$ MFMillipore membrane filter, EMD Millipore, Billerica, MA, USA; Appendix Table A.2) for identification of the bacterial and eukaryotic inhabitants. To identify the most abundant microorganisms and determine whether the presence of U(VI) influenced the diversity of microbial contaminants, a subset of $16 \mathrm{~S}$ and $18 \mathrm{~S}$ rDNA was sequenced from the source reservoir solutions and one receiving reservoir solution (cell $1.9 \mathrm{~g} / \mathrm{cm}^{3}$ ). Details regarding the microbial characterization can be found in the Appendix section A.1.

\subsection{Determination of the uranium diffusion profile}

After 2,457 days ( six years), the U(VI) diffusion experiment was stopped and the clay samples were removed from the cells. The cylindrical sample holders containing the MX-80 were shock-frozen in liquid $\mathrm{N}_{2}$. Each MX-80 sample was carefully extruded and placed on a $1 \mathrm{~mm}$-thin bed of quartz sand (p.a., Merck) in a polytetrafluoroethylene (PTFE) cylinder manufactured at Helmholtz-Zentrum Dresden-Rossendorf (HZDR). The MX-80 was dried overnight at $60{ }^{\circ} \mathrm{C}$. The next day, the MX-80 samples were combined with a stainless steel drilling sample holder (made at HZDR) and vacuum-impregnated using a "water-clear" epoxy casting resin and hardener (solid density, $\rho_{\mathrm{S}}=1.25 \mathrm{~g} / \mathrm{cm}^{3} ; \mathrm{R} \& \mathrm{G}$ Faserverbundwerkstoffe $\mathrm{GmbH}$, Waldenbuch, Germany). After hardening of the resin for one day, the PTFE cylinder was removed and the $\mathrm{U}(\mathrm{VI})$ diffusion profiles were determined with the help of the abrasive peeling 
technique (Van Loon and Eikenberg, 2005). The abraded clay fractions were extracted for their $\mathrm{U}(\mathrm{VI})$ content by $1 \mathrm{M} \mathrm{HNO}_{3}$ (p.a., Roth, Karlsruhe, Germany) and analyzed. This method has been applied in a number of earlier experiments (Joseph et al., 2013b; Sachs et al., 2007).

\subsection{Experimental uncertainties}

In the case of the HTO diffusion, the diffusion parameters were determined by fitting the temporal evolution of the diffusive HTO flux and of the accumulated HTO activity in the receiving reservoir solution. The calculated uncertainties in the HTO flux and the accumulated HTO activity were determined from the uncertainties of the following parameters (cf. Van Loon and Soler (2004)): cross section area of the bentonite sample, time of sampling, dead volume of the diffusion set-up, volume of the receiving reservoir solution, volume of the aliquot taken from each receiving reservoir solution for LSC analysis, and count rate of the LSC measurement.

The diffusion parameters for the U(VI) diffusion were obtained by fitting the U(VI) diffusion profiles in the bentonite. The experimental uncertainty of the diffusion depth was given by the average of the individual distance measurement at four points of the clay sample. For the $\mathrm{U}(\mathrm{VI})$ concentration values determined by ICP-MS, an uncertainty of $10 \%$ was assumed.

\subsection{Theory}

Both HTO and U(VI) were assumed to migrate via molecular diffusion through MX-80. The theoretical background of molecular diffusion is given, for instance, in Van Loon et al. (2003). The diffusion process through a porous medium is defined by Fick's first law:

$$
J=-D_{\mathrm{e}} \cdot \frac{\partial c}{\partial x}
$$

where $J\left[\mathrm{~mol} /\left(\mathrm{m}^{2} \cdot \mathrm{s}\right)\right]$ is the diffusive flux of a solute, $c\left[\mathrm{~mol} / \mathrm{m}^{3}\right]$ represents the tracer concentration in the mobile phase, and $x[\mathrm{~m}]$ is the spatial coordinate. The change of concentration with time, $t[\mathrm{~s}]$, is expressed by Fick's second law:

$$
\frac{\partial c}{\partial t}=D_{\mathrm{a}} \cdot \frac{\partial^{2} c}{\partial x^{2}}
$$

where $D_{\mathrm{a}}\left[\mathrm{m}^{2} / \mathrm{s}\right]$ denotes the apparent diffusion coefficient. Both diffusion coefficients are linked by the rock capacity factor $\alpha[-]$ according to: 
$D_{\mathrm{a}}=\frac{D_{\mathrm{e}}}{\alpha}$

Eq. (3)

The rock capacity factor is defined as:

$\alpha=\varepsilon_{\mathrm{eff}}+\rho \cdot K_{\mathrm{d}}$

Eq. (4)

where $\rho\left[\mathrm{kg} / \mathrm{m}^{3}\right]$ is the dry bulk density and $K_{\mathrm{d}}\left[\mathrm{m}^{3} / \mathrm{kg}\right]$ the sorption distribution coefficient. For non-sorbing tracers such as HTO with $K_{\mathrm{d}}=0$, it is assumed that $\alpha$ is equal to $\varepsilon_{\text {eff. In contrast to }}$ $D_{\mathrm{e}}, D_{\mathrm{a}}$ considers the tracer sorption to the clay. In addition, $D_{\mathrm{e}}$ is correlated to the diffusion coefficient of a species in water by:

$D_{\mathrm{e}}=\frac{\varepsilon_{\text {eff }} \cdot \delta}{\tau^{2}} \cdot D_{\mathrm{w}}$

with $\delta[-]$ as constrictivity, which describes the relation between the size of the respective diffusing species and the present pore size, and $\tau[-]$ as tortuosity, which describes to what degree the diffusion path is curved and twisted. In CrunchFlow2011 (Steefel, 2011), this relation is defined as:

$D_{\mathrm{e}}=\varepsilon_{\mathrm{eff}} \cdot \beta \cdot D_{\mathrm{w}}$

In this case, constrictivity and tortuosity are combined into one parameter, $\beta[-]$, which can only have values $\leq 1$. In the present study, $\beta$ was referred to as tortuosity.

Archie's law is commonly used to empirically describe the relation between the electrical conductivity of porous rocks and their porosity. The electrical field can be regarded as analogous to the concentration gradient. Therefore, it is possible to describe the relation between $\varepsilon_{\text {eff }}$ and $D_{\mathrm{e}}$ with this empirical formula and consequently, to predict diffusion parameters in materials with known porosity (Boving and Grathwohl, 2001):

$D_{\mathrm{e}}=\varepsilon_{\mathrm{eff}}^{m} \cdot D_{\mathrm{w}}$

where $m[-]$ is an empirical constant also known as cementation factor of sedimentary rocks. The constant $m$ depends on the properties of the porous material and is not influenced by temperature or sorption of the tracer on the porous medium.

Recently, Van Loon and Mibus (2015) have discussed the limits of Archie's law by collecting and comparing $D_{\mathrm{e}}$ values and respective $\varepsilon_{\text {eff }}$ values for several diffusing tracers and 
compacted clays. They find that for $\varepsilon_{\text {eff }} \leq 0.1$, Archie's law is not able to describe the relation between $D_{\mathrm{e}}$ and $\varepsilon_{\text {eff }}$ appropriately. They propose a small variation of Archie's law, the so-called extended Archie's law (Eq. (8)), to reproduce the data and consequently, to predict $D_{\mathrm{e}}$ values also for systems with smaller porosities.

$D_{\mathrm{e}}=\varepsilon_{\mathrm{eff}}^{m 1} \cdot D_{\mathrm{w}}+\varepsilon_{\mathrm{eff}}^{m 2} \cdot B$

where $B, m 1, m 2$ are empirical factors.

The extended Archie's law is applicable for porosities between 0.005 and 0.7 . As best fit for the majority of literature data, the following values for the empirical factors are reported: $B=$ $1 \times 10^{-10} \mathrm{~m}^{2} / \mathrm{s} ; m 1=2.4(+0.6 /-0.4) ; m 2=1.0( \pm 0.2)$.

\subsection{CrunchFlow2011 implementation}

The code CrunchFlow2011 was used to simulate the diffusion of HTO and U(VI) through bentonite and derive values for the diffusion and sorption parameters based on a fit to the experimentally obtained diffusion data. From a chemical point of view, CrunchFlow2011 simulations of $\mathrm{U}(\mathrm{VI})$ sorption were reduced to a simple $K_{\mathrm{d}}$ model (instantaneous equilibrium, full reversibility, no activity correction). Only the following primary species were considered: HTO and $\mathrm{UO}_{2}{ }^{2+}$, as respective migrating species; $\mathrm{Cl}^{-}$for charge balance; $>\mathrm{SiOH}$ and $>\mathrm{FeOH}$, as generic surface species for U(VI) sorption onto clay and stainless steel filter plates, respectively. It was assumed that HTO does not interact with the clay and filter surfaces, thus, no HTO sorption was simulated.

The CrunchFlow2011 model was composed of source reservoir, stainless steel filter, MX-80 sample, stainless steel filter, and receiving reservoir. Each part was considered as homogeneous with regard to their transport properties. Details about the model set-up can be found in Appendix section A.2. For both HTO and U(VI) models, constant conditions (Eq. (9)) at the source reservoir and varying conditions at the receiving reservoir were used (Eq. (10)).

$c(x=0, t>0)=c_{0}=$ const.

Eq. (9)

$c(x=L, t>0)=f_{L}(t)$

where $L[\mathrm{~m}]$ denotes the thickness of the system filter/clay/filter. During HTO diffusion modeling, the filters, the MX-80 as well as the receiving reservoir solution were regarded as initially free of tracer; whereas, for U(VI) diffusion modeling, an initial U(VI) concentration, 
$c_{\text {initial, was assumed. }}$

For comparison with the experimental data, in the case of the HTO diffusion, the HTO concentration in the node of the receiving reservoir was determined at specified time points (the experimental sampling days). In the case of the U(VI) diffusion, two output files were relevant for comparison with the experimentally obtained profile and out-diffusion data. The first was the uranium content in the clay as a function of distance at the end of the diffusion experiment, and the second was the $\mathrm{U}(\mathrm{VI})$ concentration in the receiving reservoir at the time points when the solution was replaced.

The diffusion coefficient of HTO in water, $D_{\mathrm{w}}(\mathrm{HTO})\left[\mathrm{m}^{2} / \mathrm{s}\right]$, was based on the value reported in Glaus et al. (2008) $\left(D_{\mathrm{w}}(\mathrm{HTO})=2.2 \times 10^{-9} \mathrm{~m}^{2} / \mathrm{s}\right)$. As the diffusion coefficient of U(VI) in water, $D_{\mathrm{w}}(\mathrm{U}(\mathrm{VI}))$, the value published for $\mathrm{Ca}_{2} \mathrm{UO}_{2}\left(\mathrm{CO}_{3}\right)_{3}(\mathrm{aq})$ by Kerisit and Liu (2010) $\left(D_{\mathrm{w}}(\mathrm{U}(\mathrm{VI}))=4.6 \times 10^{-10} \mathrm{~m}^{2} / \mathrm{s}\right)$ was used. A tortuosity was assigned for each domain. The tortuosities of the source and receiving reservoir solution (if part of discretization) were set to 1.0. The filter tortuosity was calculated based on Eq. (6). In the case of HTO, $D_{\mathrm{w}}(\mathrm{HTO})$,

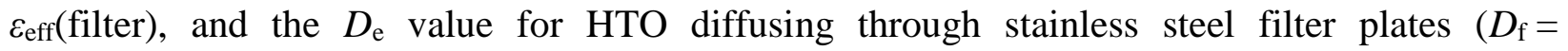
$2.3 \times 10^{-10} \mathrm{~m}^{2} / \mathrm{s}$; Glaus et al. (2008)) were used. In the case of U(VI), $D_{\mathrm{f}}$ was estimated by $D_{\mathrm{f}}=$ $D_{\mathrm{w}} / 10$ (Glaus et al., 2008). The clay tortuosity in both model approaches was a fitting parameter.

To model U(VI) diffusion, the fitted $\varepsilon_{\text {eff }}(\mathrm{HTO})$ values were incorporated into the model assuming that these were equal to the $\varepsilon_{\mathrm{eff}}(\mathrm{U}(\mathrm{VI}))$ values. Quartz was implemented as model mineral for MX-80 and volume-balancing solid phase in the model. The $K_{\mathrm{d}}$ of U(VI) sorption to MX-80 were fit by adjusting the binding site density of quartz, [>SiOH]. The relationship between these parameters is shown in Eq. (11). As the starting point for the fitting procedure, a $\log K$ value for the $\mathrm{UO}_{2}{ }^{2+}$ sorption onto quartz was pre-defined as $\log K=-1.77$ in the model database. This value was based on the $K_{\mathrm{d}}$ value for the sorption of $\mathrm{Ca}_{2} \mathrm{UO}_{2}\left(\mathrm{CO}_{3}\right)_{3}(\mathrm{aq})$ to Opalinus Clay of $0.0222 \mathrm{~kg} / \mathrm{m}^{3}$ (Joseph et al., 2011) assuming a specific surface area (SSA) of $100 \mathrm{~m}^{2} / \mathrm{g}$ (montmorillonite; Payne et al. (2011)) and a generic binding site density of $2.31 \mathrm{sites} / \mathrm{nm}^{2}\left(=3.8 \cdot 10^{-6} \mathrm{~mol} / \mathrm{m}^{2}\right.$; Davis and Kent $\left.(1990)\right)$.

$\log K=\log \left(\frac{[>\mathrm{SiOH}]}{K_{\mathrm{d}}} \cdot \mathrm{SSA}\right)$

To fit the U(VI) diffusion data, the binding site density [>SiOH] was adjusted using the PEST 
parameter optimization tool described in section 2.8. Since $\log K$ and SSA were constant throughout the fitting procedure, the optimized $[>\mathrm{SiOH}]$ value was related to $K_{\mathrm{d}}$ by applying Eq. (11).

The U(VI) sorption to the stainless steel filter plates was determined after the diffusion experiment by acid extraction with $1 \mathrm{M} \mathrm{HNO}_{3}$ for one week. With increasing clay bulk density and changes in the pore water composition, $\mathrm{U}(\mathrm{VI})$ sorption to the filters increased slightly. However, in all cases, the $K_{\mathrm{d}}$ value was quite low. The sorption of U(VI) to the filter plates was incorporated in the model by defining a $\log K\left(>\mathrm{FeOHUO}_{2}{ }^{2+}\right)$ that reflects the measured $K_{\mathrm{d}}$ values (Appendix Table A.3).

To maintain the U(VI) concentration below $1 \%$ of the source reservoir concentration, the receiving reservoir solution was regularly replaced by fresh pore water. During the six year diffusion experiment, there were several events where circulation of solution through the diffusion cell end plates was stopped (e.g., tubing exchange, broken pump). Both the number of solution replacements and the conservatively estimated total stops are summarized in Table 4. Both (i) the regular exchange of the receiving reservoir solution and (ii) unplanned stops in pore water circulation were accounted for in the model (see Appendix section A.2 and Fig. A.1). A summary of the parameters that were kept constant in both models is reported in Table 5 .

Table 4: Amount of replacements of the receiving reservoir solutions and total duration of no solution circulation (conservative estimation) through the diffusion cell end plates for the U(VI) diffusion through MX-80 as a function of dry bulk density investigated.

\begin{tabular}{llcl}
\hline $\boldsymbol{\rho} / \mathbf{g} / \mathbf{c m}^{\mathbf{3}}$ & $\mathbf{1 . 3}$ & $\mathbf{1 . 6}$ & $\mathbf{1 . 9}$ \\
\hline No. of replacements & 35 & 20 & 20 \\
Total stops / days & 61 & 298 & 302 \\
\hline
\end{tabular}


Table 5: Overview of the parameters used in the CrunchFlow2011 input files for modeling the HTO and U(VI) diffusion through MX-80 independent of the dry bulk density investigated.

\begin{tabular}{llll}
\hline Domain & Parameter & \multicolumn{2}{c}{ Value in the } \\
& & HTO model & U(VI) model \\
\hline Overall & $t / \mathrm{d}$ & 13.05 & 2457 \\
& $D_{\mathrm{w}} / \mathrm{m}^{2} / \mathrm{s}$ & $2.2 \times 10^{-9}$ & $4.6 \times 10^{-10}$ \\
& $\varepsilon_{\mathrm{eff}}$ & $1.0^{\mathrm{a}}$ & 2600 \\
Source reservoir & $\beta$ & $-\mathrm{a}$ & 1.0 \\
& $\rho_{\mathrm{S}} / \mathrm{g} / \mathrm{cm}^{3}$ & 5.27 & 5.27 \\
Stainless steel filter plates & $\varepsilon_{\mathrm{eff}}$ & 0.3 & 0.3 \\
& $\beta$ & 0.35 & 0.33 \\
& $\rho_{\mathrm{S}} / \mathrm{g} / \mathrm{cm}^{3}$ & 2.65 & $-\mathrm{b}$ \\
MX-80 bentonite & $\varepsilon_{\mathrm{eff}}$ & 2600 & 643 \\
\hline & $\beta$ & 1.0 & 1.0 \\
\hline
\end{tabular}

${ }^{a}$ The source reservoir was not incorporated in the discretization. There was no increase of $\varepsilon_{\text {eff }}$ and no definition of $\beta$ needed (cf. Appendix section A.2).

${ }^{\mathrm{b}}$ varied in dependence on $\varepsilon_{\text {eff }}(\mathrm{HTO})$ and $\rho$

\subsection{PEST estimation}

The parameter estimation code PEST (Doherty, 2003) was used to minimize the differences between the output file data of CrunchFlow2011 and the experimental diffusion data by changing pre-defined CrunchFlow2011 input parameters.

When fitting HTO diffusion, the weighting factor was $1 / \Delta c$, where $\Delta c[\mathrm{M}]$ describes the uncertainty of the measured HTO concentration. When fitting the U(VI) profile, the weighting factor was $1 / d$, where $d$ denotes the distance to the clay edge [mm]. When the U(VI) outdiffusion in the receiving reservoir solution, $1 / c$ was used as a weighting factor, where $c$ denotes the $\mathrm{U}(\mathrm{VI})$ concentration in the receiving reservoir at the time the solution was replaced. The relevant diffusion parameters and their fitting equivalents for HTO and $\mathrm{U}(\mathrm{VI})$ diffusion modeling are shown in Table 6 , where $c(\mathrm{U}(\mathrm{VI}))_{\mathrm{BG}}$ denotes the background $\mathrm{U}(\mathrm{VI})$ concentration in the clay. 
Table 6: Overview of the diffusion parameters and their fitting equivalents varied in the MX-80 in the CrunchFlow2011 input files using the PEST optimization code.

\begin{tabular}{|c|c|c|c|c|c|c|}
\hline \multirow{2}{*}{$\begin{array}{l}\text { Model } \\
\text { Diffusion parameter }\end{array}$} & \multicolumn{2}{|c|}{ HTO through-diffusion } & \multicolumn{2}{|r|}{$\mathrm{U}(\mathrm{VI})$ profile } & \multicolumn{2}{|c|}{ U(VI) out-diffusion ${ }^{\text {a }}$} \\
\hline & $D_{\mathrm{e}}$ & $\varepsilon_{\mathrm{eff}}$ & $K_{\mathrm{d}}$ & $c(\mathrm{U}(\mathrm{VI}))_{\mathrm{BG}}$ & $D_{\mathrm{e}}, D_{\mathrm{a}}$ & $D_{\mathrm{e}}, D_{\mathrm{a}}$ \\
\hline Fitting equivalent & $\beta$ & $\varepsilon_{\mathrm{eff}}$ & {$[>\mathrm{SiOH}]$} & $c(\mathrm{U}(\mathrm{VI}))_{\mathrm{BG}}$ & $\beta$ & $\beta$ \\
\hline
\end{tabular}

${ }^{\text {a }}$ Only one parameter was fit due to the strong correlation between $\beta,[>\mathrm{SiOH}]$, and $c(\mathrm{U}(\mathrm{VI}))_{\mathrm{BG}}$.

\subsection{COMSOL Multiphysics® 5.0}

To build confidence in the parameter fitting results obtained by CrunchFlow2011 and PEST, COMSOL Multiphysics ${ }^{\circledR} 5.0$ (COMSOL, 2014) was used. Here, a one-dimensional model consisting of source reservoir, filter, clay, filter, and receiving reservoir was defined using an extremely fine mesh (maximum element size: $8.4 \times 10^{-5} \mathrm{~m}$ ) to simulate the U(VI) diffusion. The optimized CrunchFlow2011/PEST model parameters were used in the COMSOL simulations. No chemical species had to be defined, since the molecular diffusion through a porous medium was investigated from the physical point of view only. The regular replacements of the receiving reservoir solution and the irregular pump stops were not considered in the model since they had only a minor influence on the diffusion parameters obtained by fitting the diffusion profile with CrunchFlow2011. The U(VI) profile in the clay at the end of the diffusion experiment was extracted from the model and compared with the respective experimental data. 


\section{Results and discussion}

\subsection{Swelling behavior of bentonite}

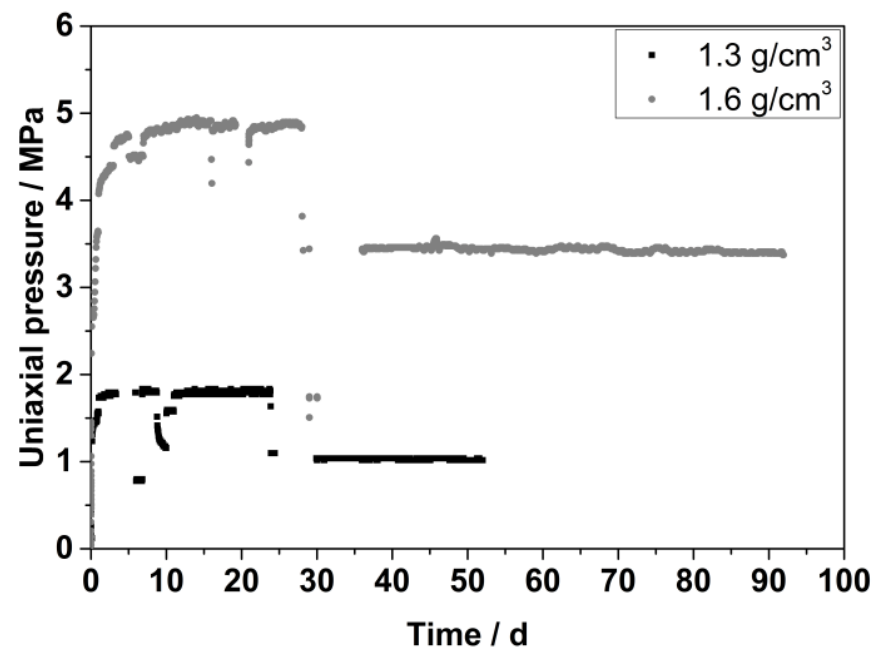

Fig. 2: Swelling pressure measured for the diffusion cells with $\rho=1.3$ and $1.6 \mathrm{~g} / \mathrm{cm}^{3}$ as a function of time.

The measured swelling pressures for the diffusion cells with $\rho$ of 1.3 and $1.6 \mathrm{~g} / \mathrm{cm}^{3}$ are shown in Fig. 2. At $1.3 \mathrm{~g} / \mathrm{cm}^{3}$ and $1.6 \mathrm{~g} / \mathrm{cm}^{3}$, swelling pressure reached equilibrium within 30 days at about $1 \mathrm{MPa}$ and within 35 days at about $3.5 \mathrm{MPa}$, respectively. The intense drops of pressure before equilibrium establishment were attributed to changes in the hydraulic pressure of the HPLC pump (Appendix Table A.1). Lee et al. (2012) investigated the swelling pressure of Ca-bentonite as a function of dry density, ionic strength, and time. Under comparable conditions as used in this study, they observed that the steady-state region is reached after 20 days, which agrees well with the present results. It was assumed that after the respective time periods, the MX-80 samples were fully saturated.

\subsection{Aqueous U(VI) speciation}

Appendix Table A.4 summarizes the composition of the experimentally prepared pore water in the source reservoir in the first and the last year of the diffusion experiment for all three dry bulk densities investigated. The comparison of the composition (e.g., $\left.c(\mathrm{Na})=2.0-3.2 \times 10^{-1} \mathrm{M}\right)$ and ionic strength $(I=0.28-0.41 \mathrm{M})$ of the solutions shows that their salinity increased with time. This could be attributed to water evaporation over the long time period the experiment was conducted. Within this time, the source reservoir solutions were never exchanged. However, all 
reservoir solutions were replaced by fresh ones in the last year at $t=2401$ days. The experiment was stopped at $t=2457$ days. The composition of this second set of solutions is summarized in Table A.5.

The speciation results are presented in Tables A.4 and A.5. The $\mathrm{Ca}_{2} \mathrm{UO}_{2}\left(\mathrm{CO}_{3}\right)_{3}$ (aq) complex dominates the speciation in all solutions and consequently, can be assumed to be the main diffusing U(VI) compound. Since $\mathrm{Ca}_{2} \mathrm{UO}_{2}\left(\mathrm{CO}_{3}\right)_{3}(\mathrm{aq})$ is a neutral species, it will not be repulsed by the negatively charged clay surface and the main part of the interparticle space would be accessible. Bernhard et al. (2001) investigated this complex by extended X-ray absorption finestructure spectroscopy. Based on their results and taking into account the radii of calcium and oxygen, a diameter between 10-11 $\AA$ for the unhydrated complex was estimated. Given this large size, the $\mathrm{Ca}_{2} \mathrm{UO}_{2}\left(\mathrm{CO}_{3}\right)_{3}(\mathrm{aq})$ complex may not have access to the interlayers of the montmorillonite fraction of MX-80. Depending on how many water layers are present, the montmorillonite interlayer dimension can range from 2 to $10 \AA$ (Bradbury and Baeyens, 2002; Keren and Shainberg, 1975). In this study, $\varepsilon_{\text {eff }}$ of HTO was used in the U(VI) diffusion model. However, it appears likely that $\varepsilon_{\text {eff }}$ of U(VI) is smaller than that of HTO. Joseph et al. (2013b) reported that the choice of $\varepsilon_{\text {eff }}$ has no significant impact on the modeled U(VI) diffusion parameters, since the U(VI) sorption onto the clay dominates (cf. Eq. (4): $\rho \cdot K_{\mathrm{d}} \gg \varepsilon_{\mathrm{eff}}$ ).

\subsection{Biological contaminants}

Despite the presence of $\mathrm{NaF}\left(c \approx 2 \times 10^{-4} \mathrm{M}\right)$ and the oligotrophic nature of the reservoir solutions, eukaryotic and prokaryotic microorganisms were detected within each reservoir after six years, including those with $1 \times 10^{-6} \mathrm{M} \mathrm{U}(\mathrm{VI})$. Surprisingly, the majority of bacteria are heterotrophs (cf. Appendix Table A.6), despite the low levels of dissolved organic carbon. Exceptions include the green sulfur family Chlorobiales, which are photoautotrophs. The prokaryotic diversity in the source and receiving reservoir solution of the $\rho=1.9 \mathrm{~g} / \mathrm{cm}^{3}$ diffusion cell included bacteria from the Planctomyces genus and Rhodospirillales order. The Planctomyces genus dominated the diversity of both reservoirs. In all other diffusion cells, prokaryotic families were only present in the source or receiving reservoir solution, but not in both, leading to the conclusion that the solutions should be regarded as independent. Their prokaryotic diversity could not be attributed to spores or microorganisms that were originally contained in the bentonite sample since all diffusion cells contained the same compacted MX-80. 
In the case of eukaryotic diversity, in all reservoir solutions investigated, fungi species (Ascomycota phylum) were identified (cf. Appendix Table A.7).

In this study, it was assumed that the various prokaryotic and eukaryotic species present in the reservoir solutions had no impact on the uranium diffusion path. In particular, in the samples with $\rho>1.45 \mathrm{~g} / \mathrm{cm}^{3}$, the clay pores should have been too narrow to allow microorganisms to be active within the clay (Stroes-Gascoyne, 2011). In addition, the solutions were regularly filtered and the tubing between the solutions and diffusion cells was regularly exchanged to guarantee the unhindered flow of solution through the end plates of the diffusion cells. The filtered solutions had a U(VI) concentration of about $1 \times 10^{-6} \mathrm{M}$. Thus, a biotransformation of the U(VI) to insoluble uranium species could be excluded. However, the release of organic compounds by the detected microorganisms to the pore water solutions, which could affect the U(VI) speciation, could not be ruled out. The TOC levels were determined for each solution (Appendix Tables A.6 and A.7), but the organic compounds were not analyzed in detail.

\subsection{HTO diffusion through MX-80 as a function of density}

Before the U(VI) diffusion experiments were started, an HTO diffusion experiment was conducted to determine the HTO transport porosity and to demonstrate that the applied experimental set-up produces parameter values that were comparable to literature data. In this study, a single-porosity pore scale model was assumed, although it was recently shown that for Na-montmorillonite a dual-porosity model better describes the present clay microstructure (Tinnacher et al., 2016). Table 7 summarizes the HTO diffusion parameters used in and obtained by fitting of the experimental results for the three investigated dry bulk densities (Appendix Fig. A.2). As expected, $\varepsilon_{\text {eff }}$ and $\beta$ decrease with increasing MX-80 dry density, since the diffusion available pore space decreased and the tortuosity increased with increasing clay compaction. Both parameters contributed to the decrease of $D_{\mathrm{e}}$ with increasing clay density. The unusually high porosity at $\rho=1.6 \mathrm{~g} / \mathrm{cm}^{3}$ seemed to be an outlier. It may be attributed to phase heterogeneities in the clay sample caused by the HPLC pump during the saturation process. However, during abrasive peeling at the end of the U(VI) diffusion experiment, no heterogeneities were observed. The comparison of the results with literature values showed quite good agreement, in particular with the values from Glaus et al. (2010), which have been obtained for $\rho=1.9 \mathrm{~g} / \mathrm{cm}^{3}$. 
Table 7: Parameter values of HTO diffusion through MX-80 as a function of dry bulk density obtained in this study and compared to literature values.

\begin{tabular}{|c|c|c|c|}
\hline$\rho / \mathrm{g} / \mathrm{cm}^{3}$ & 1.3 & 1.6 & 1.9 \\
\hline \multicolumn{4}{|l|}{ Parameter } \\
\hline$c_{0} / \mathrm{M}$ & $2.25 \times 10^{-10}$ & $2.24 \times 10^{-10}$ & $2.20 \times 10^{-10}$ \\
\hline$\varepsilon_{\text {eff }} /-^{\mathrm{a}}$ & $0.65 \pm 0.11$ & $0.62 \pm 0.09$ & $0.31 \pm 0.08$ \\
\hline$\beta / \times 10^{-2}$ a & $9.2 \pm 1.4$ & $6.1 \pm 0.7$ & $4.8 \pm 0.9$ \\
\hline$D_{\mathrm{e}} / \times 10^{-11} \mathrm{~m}^{2} / \mathrm{s}^{\mathrm{a}}$ & $13.2 \pm 4.1$ & $8.4 \pm 2.2$ & $3.4 \pm 1.4$ \\
\hline$\varepsilon_{\text {eff }} /-{ }^{b}$ & & & $0.38 \pm 0.05 / 0.41 \pm 0.06$ \\
\hline$D_{\mathrm{e}} / \times 10^{-11} \mathrm{~m}^{2} / \mathrm{s}^{\mathrm{b}}$ & & & $1.7 \pm 0.2 / 1.9 \pm 0.2$ \\
\hline$\varepsilon_{\text {eff }} /-^{c}$ & & $0.44 \pm 0.02$ & $0.40 \pm 0.02 / 0.35 \pm 0.02$ \\
\hline$D_{\mathrm{e}} / \times 10^{-11} \mathrm{~m}^{2} / \mathrm{s}^{\mathrm{c}}$ & & $11.2 \pm 0.6$ & $5.9 \pm 0.3 / 5.2 \pm 0.4$ \\
\hline
\end{tabular}

\footnotetext{
a The parameter uncertainties are reported in the form of $95 \%$ confidence limits as provided by PEST after the fitting procedure.

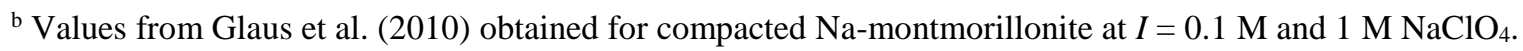

${ }^{c}$ Values from Wu et al. (2012) obtained for GMZ bentonite at dry densities of 1.6, 1.8, and $2.0 \mathrm{~g} / \mathrm{cm}^{3}$.
}

Fig. 3 shows the relationship between the values of $D_{\mathrm{e}}$ and $\varepsilon_{\text {eff }}$ obtained in this study. The data were fit using Archie's law (Eq. (7)) with $D_{\mathrm{w}}(\mathrm{HTO})$ (Table 5). The empirical constant calculated from the linear fit agreed well with the cementation factor of $4.5 \pm 1.0$ determined by Wu et al. (2012) for HTO diffusion through GMZ bentonite (with $D_{\mathrm{w}}(\mathrm{HTO})=2.3 \times 10^{-9} \mathrm{~m}^{2} / \mathrm{s}$ ).

Glaus et al. (2010) used $D_{\mathrm{w}}(\mathrm{HTO})$ as a fitting parameter, $A$. They obtain values of $A=9.8 \times 10^{-11} \mathrm{~m}^{2} / \mathrm{s}$ and $m=1.81$ for the HTO diffusion through compacted Na-montmorillonite. If this model is applied to the data in the present study, values of $A=(2.1 \pm 0.8) \times 10^{-10} \mathrm{~m}^{2} / \mathrm{s}$ and $m=1.6 \pm 0.6$ are the result. The values are in reasonable agreement with Glaus et al. (2010). The somewhat higher $A$ value in the present study can be attributed to the unusually high $\varepsilon_{\text {eff }}$ at $1.6 \mathrm{~g} / \mathrm{cm}^{3}$. Nevertheless, the agreement with literature values demonstrates the applicability of the present experimental set-up. 


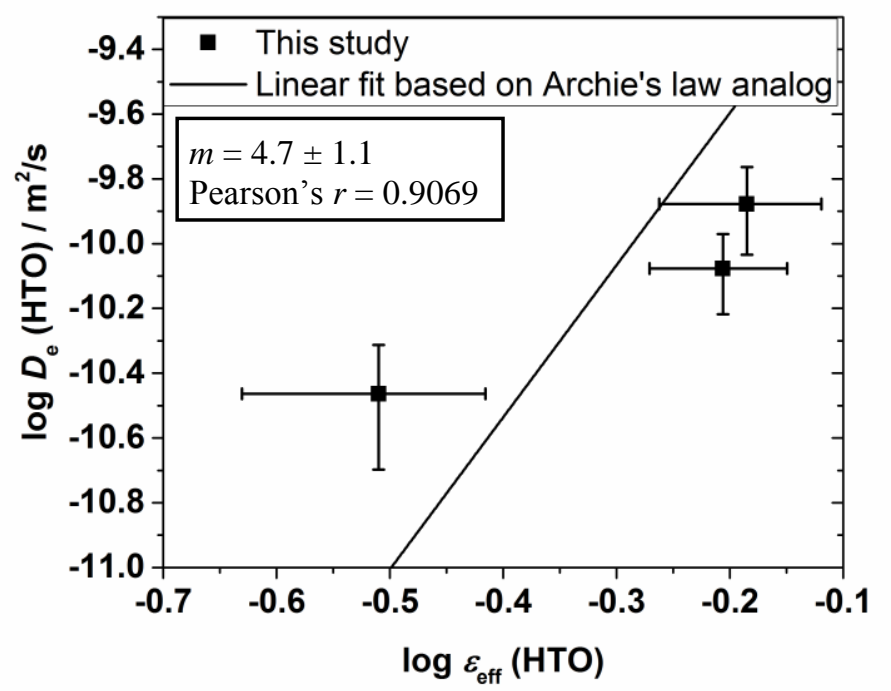

Fig. 3: Relation between $D_{\mathrm{e}}$ and $\varepsilon_{\mathrm{eff}}$ for the HTO diffusion through MX-80 bentonite (error of empirical constant $m: 1 \sigma)$.

\subsection{U(VI) diffusion in MX-80 as a function of density}

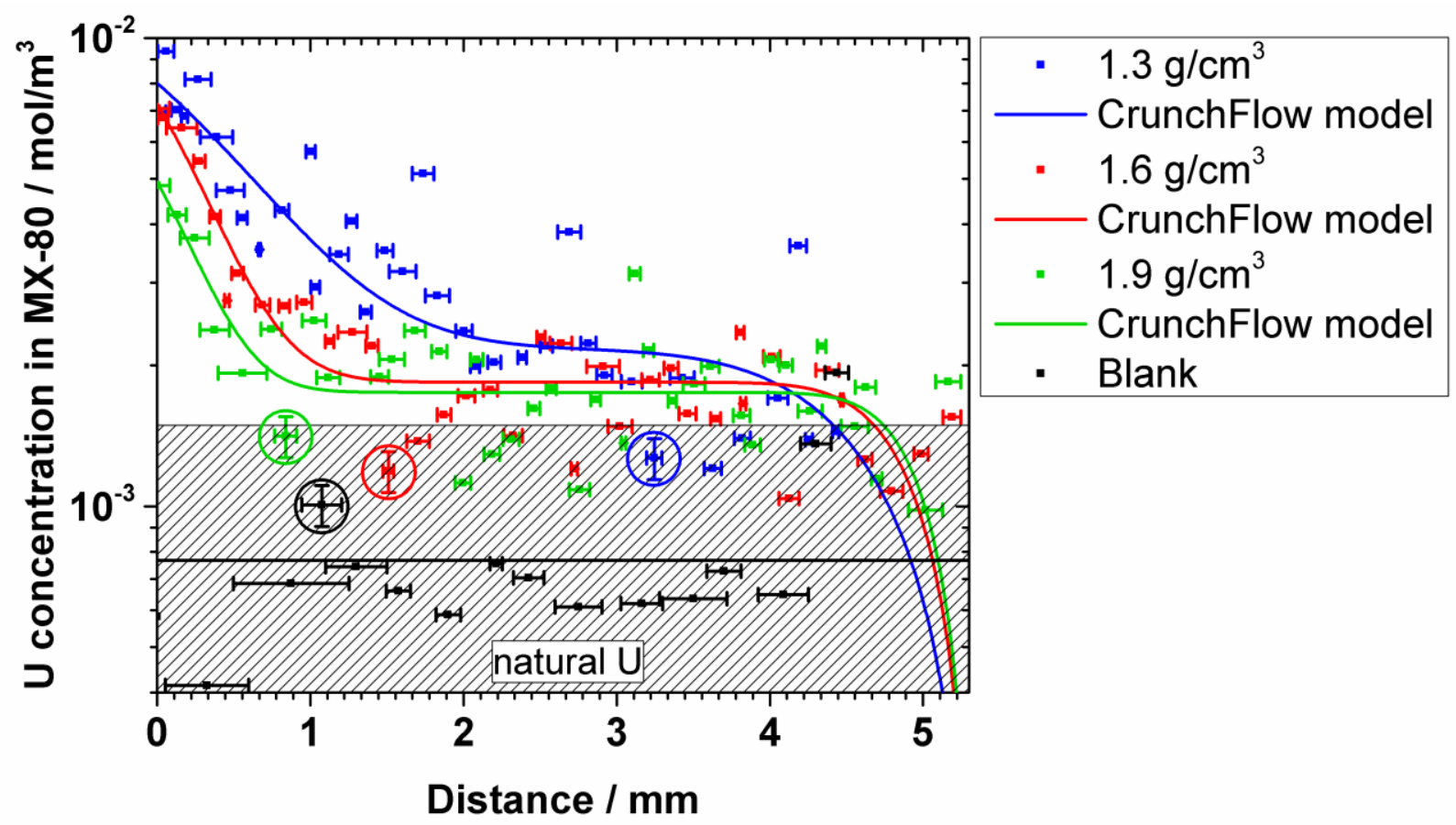

Fig. 4: Concentration depth profile of uranium in MX-80 as a function of clay dry density. To reduce clutter, the error of the experimental $\mathrm{U}$ concentration in MX-80 is given only once per data set (highlighted by circles). 
In Fig. 4, the uranium depth profiles for $\mathrm{U}(\mathrm{VI})$ diffusion into MX-80 as a function of dry density are presented together with the best-fit curves from the CrunchFlow/PEST modeling. In addition, the uranium profile of the blank diffusion cell is depicted (black dots). The average uranium concentration measured in this clay sample is shown by the black line within the shaded area (error: $2 \sigma$ ). It is defined as the background uranium concentration in MX-80, which was used as guidance for the natural uranium level in all MX-80 samples investigated. The added uranium diffused about $3 \mathrm{~mm}, 1.5 \mathrm{~mm}$, and $1 \mathrm{~mm}$ into the clay at $\rho=1.3,1.6$, and $1.9 \mathrm{~g} / \mathrm{cm}^{3}$, over six years, respectively. Even after this time, uranium did not diffuse through the entire MX-80 samples $\left(5.3 \times 10^{-3} \mathrm{~m}\right.$, cf. Table 3$)$.

The reliability of the CrunchFlow2011 model was validated by using the best-fit values of the diffusion parameters in a second model created by COMSOL Multiphysics® 5.0 (COMSOL, 2014). As shown in Fig. A.3 the obtained profiles are similar to the profiles obtained with the CrunchFlow model and provided confidence in the CrunchFlow modeling approach.

During the performance of the $\mathrm{U}(\mathrm{VI})$ diffusion experiment, $\mathrm{U}(\mathrm{VI})$ was detected in the receiving reservoir solution. This was attributed to the continuous dissolution of natural uranium contained in the clay. In the model, the leaching of natural uranium from the clay-rich rock and its transport to the receiving reservoir solution was considered. This caused the decrease of the simulated uranium concentration in MX-80 to a depth of about $5 \mathrm{~mm}$ (Fig. 4). The experimentally determined $\mathrm{U}(\mathrm{VI})$ concentration in the receiving reservoir solution of the $1.6 \mathrm{~g} / \mathrm{cm}^{3}$ cell is presented in Fig. 5 (red dots). Relatively high U(VI) concentrations were detected over the course of the experiment. As a result, the solution was regularly replaced by fresh background electrolyte (black arrows, Fig. 5) to guarantee constant boundary conditions. By comparing these data with the $\mathrm{U}(\mathrm{VI})$ concentration measured in one of the blank cell reservoirs (black dots), it was apparent that both cells exhibited similar U(VI) leaching behavior. This indicates that the measured $\mathrm{U}(\mathrm{VI})$ concentration in the receiving reservoir solution of the $1.6 \mathrm{~g} / \mathrm{cm}^{3}$ diffusion cell represents natural uranium leached out from the MX-80. This conclusion is consistent with the diffusion depth profiling results. Uranium did not diffuse through the samples within six years. 


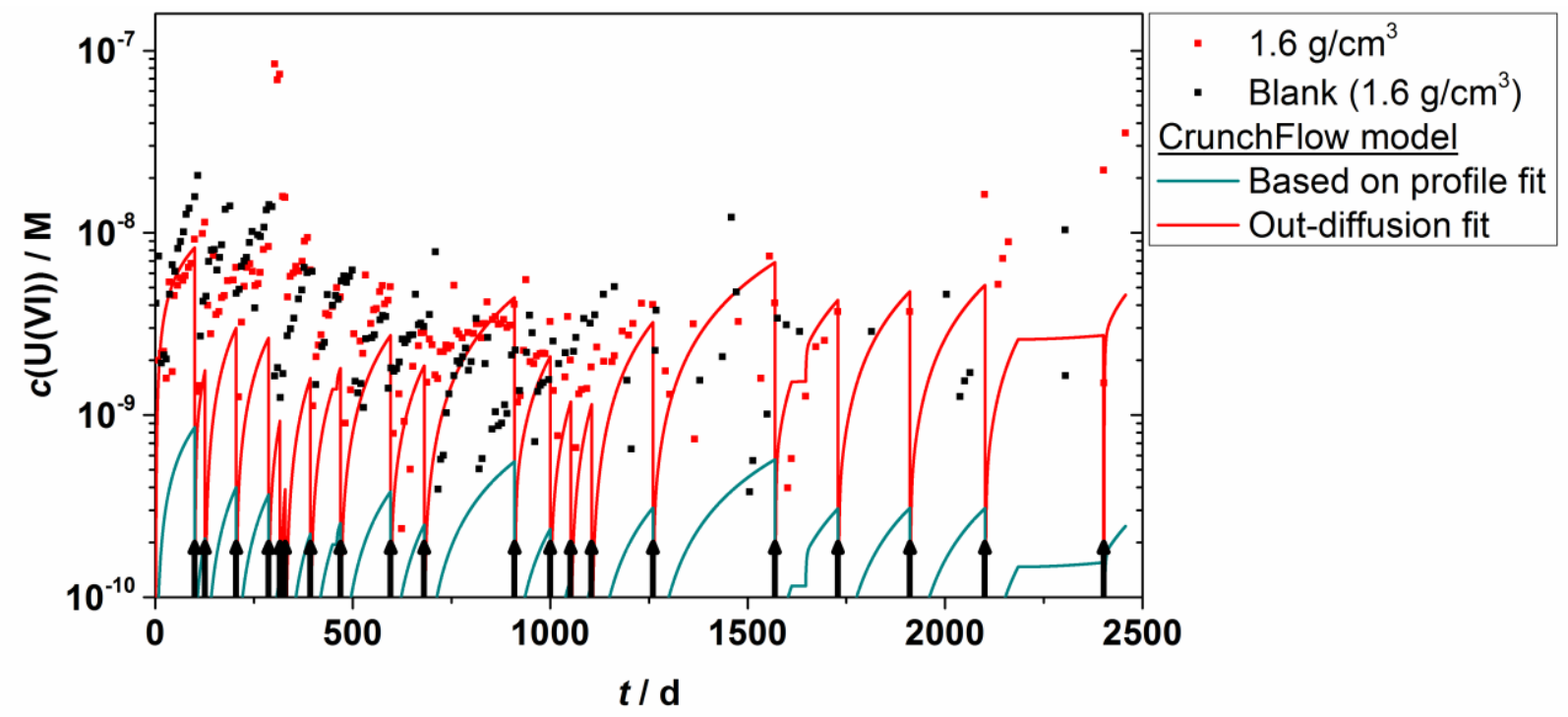

Fig. 5: $\mathrm{U}(\mathrm{VI})$ concentration in the receiving reservoir solution of diffusion cell $1.6 \mathrm{~g} / \mathrm{cm}^{3}$ as a function of time. CrunchFlow model data obtained by fitting the uranium depth profile in MX- 80 and the uranium outdiffusion in the receiving reservoir. Black arrows represent time points when the reservoir solution was replaced.

After the fitting procedure of the uranium depth profiles, the fitted parameters were used to simulate the changes in the $\mathrm{U}(\mathrm{VI})$ concentration in the receiving reservoir solution (blue line, Fig. 5). Clearly, this simulation did not fit the experimental observations. Thus, in a second fitting approach, the U(VI) concentration in the receiving reservoir solution was fit using tortuosity (Table 6) as a fitting parameter. A reasonably good agreement between experiment and model data was achieved (red line, Fig. 5). However, the best-fit tortuosity value from this outdiffusion fit was about two orders of magnitude higher than the uranium depth profile fit value (Table 8). This discrepancy indicated that the in- and out-diffusion of U(VI) in MX-80 had to be regarded independently in this study.

Table 8 summarizes the diffusion parameter values used in and obtained by modeling and fitting of the $\mathrm{U}(\mathrm{VI})$ diffusion depth profiles and the $\mathrm{U}(\mathrm{VI})$ concentration evolutions in the receiving reservoir solutions as a function of MX-80 dry density. The $K_{\mathrm{d}}$ values obtained were very low. This could be explained by the U(VI) speciation (Appendix Table A.4). The dominant neutral $\mathrm{Ca}_{2} \mathrm{UO}_{2}\left(\mathrm{CO}_{3}\right)_{3}$ (aq) complex and is known to sorb only weakly to minerals (Fox et al., 2006) and clay-rich rock (Joseph et al., 2011). In addition, $\mathrm{UO}_{2}\left(\mathrm{CO}_{3}\right)_{3}{ }^{4-}$, the second dominant species in solution, is regarded as a non-sorbing species (Joseph et al., 2013a; Křepelová et al., 2006) since it will be repulsed by the negatively charged clay surface. The low $K_{\mathrm{d}}$ values suggest 
that $\mathrm{U}(\mathrm{VI})$ reduction to $\mathrm{U}(\mathrm{IV})$ was negligible in these experiments, although the redox state of uranium sorbed to MX-80 was not experimentally verified. The obtained $K_{\mathrm{d}}$ values were all in the same order of magnitude (varying by a factor of two) and tended to lower values with increasing $\rho$. The $K_{\mathrm{d}}$ variance may be attributed to small changes in the composition of the pore waters used in the three diffusion experiments (Table 2). Due to the decreases in $K_{\mathrm{d}}$ and $\varepsilon_{\text {eff, }} \alpha$ decreased with increasing $\rho$ (cf. Eq. (4)).

Table 8: Parameter values of the U(VI) diffusion in MX-80 based on modeling the uranium depth profile in the clay and the uranium out-diffusion in the receiving reservoir as a function of dry bulk density.

\begin{tabular}{|c|c|c|c|c|c|c|}
\hline \multirow{2}{*}{$\begin{array}{l}\rho / \mathrm{g} / \mathrm{cm}^{3} \\
\text { Fit of }\end{array}$} & \multicolumn{2}{|c|}{1.3} & \multicolumn{2}{|c|}{1.6} & \multicolumn{2}{|c|}{1.9} \\
\hline & profile & out-diffusion & profile & out-diffusion & profile & out-diffusion \\
\hline \multicolumn{7}{|l|}{ Parameter $^{\text {a }}$} \\
\hline$\rho_{\mathrm{S}} / \mathrm{g} / \mathrm{cm}^{3}$ & \multicolumn{2}{|c|}{3.75} & \multicolumn{2}{|c|}{4.24} & \multicolumn{2}{|c|}{2.75} \\
\hline$\varepsilon_{\text {eff }} /-$ & \multicolumn{2}{|c|}{$0.65 \pm 0.11$} & \multicolumn{2}{|c|}{$0.62 \pm 0.09$} & \multicolumn{2}{|c|}{$0.31 \pm 0.08$} \\
\hline$c(\mathrm{U}(\mathrm{VI}))_{\text {initial }} / \mathrm{M}^{\mathrm{b}}$ & \multicolumn{2}{|c|}{$3.87 \times 10^{-10}$} & \multicolumn{2}{|c|}{$4.2 \times 10^{-12}$} & \multicolumn{2}{|c|}{$4.2 \times 10^{-12}$} \\
\hline$c(\mathrm{U}(\mathrm{VI}))_{\mathrm{BG}} / \times 10^{-7} \mathrm{M}$ & \multicolumn{2}{|c|}{$3 \pm 1$} & \multicolumn{2}{|c|}{$2.4 \pm 0.3$} & \multicolumn{2}{|c|}{$3.4 \pm 1.0$} \\
\hline$[>\mathrm{SiOH}] / \times 10^{-7} \mathrm{~mol} / \mathrm{m}^{2}$ & \multicolumn{2}{|c|}{$10 \pm 1$} & \multicolumn{2}{|c|}{$7.5 \pm 0.4$} & \multicolumn{2}{|c|}{$4.4 \pm 1.4$} \\
\hline$K_{\mathrm{d}} / \times 10^{-3} \mathrm{~m}^{3} / \mathrm{kg}$ & \multicolumn{2}{|c|}{$5.8 \pm 0.6$} & \multicolumn{2}{|c|}{$4.4 \pm 0.2$} & \multicolumn{2}{|c|}{$2.6 \pm 0.8$} \\
\hline$\alpha /-$ & \multicolumn{2}{|c|}{$8.2 \pm 0.8$} & \multicolumn{2}{|c|}{$7.6 \pm 0.4$} & \multicolumn{2}{|c|}{$5.2 \pm 1.5$} \\
\hline$\beta / \times 10^{-5}$ & $5.4 \pm 3.4$ & $340 \pm 80$ & $1.6 \pm 0.4$ & $77 \pm 25$ & $1.5 \pm 1.6$ & $59 \pm 20$ \\
\hline$D_{\mathrm{e}} / \times 10^{-15} \mathrm{~m}^{2} / \mathrm{s}$ & $16 \pm 10$ & $1030 \pm 240$ & $4.5 \pm 1.2$ & $220 \pm 70$ & $2.1 \pm 2.3$ & $83 \pm 28$ \\
\hline$D_{\mathrm{a}} / \times 10^{-16} \mathrm{~m}^{2} / \mathrm{s}$ & $20 \pm 11$ & $1200 \pm 300$ & $5.9 \pm 1.2$ & $290 \pm 90$ & $4.0 \pm 3.5$ & $160 \pm 50$ \\
\hline
\end{tabular}

\footnotetext{
${ }^{a}$ The parameter uncertainties are reported in the form of $95 \%$ confidence limits as provided by PEST after the fitting procedure.

${ }^{\mathrm{b}}$ Initial uranium concentration assumed in the filters and the receiving reservoir based on the minimal uranium concentration measured in the respective receiving reservoir.
} 
Table 9: Selection of $K_{\mathrm{d}}$ values from the literature obtained by diffusion as well as batch sorption experiments.

\begin{tabular}{|c|c|c|c|c|c|c|}
\hline & Clay type & $\begin{array}{l}\text { Background } \\
\text { electrolyte }\end{array}$ & pH & {$[\mathbf{U}(\mathbf{V I})] / \mathbf{M}$} & $K_{\mathrm{d}} / \times 10^{-3} \mathrm{~m}^{3} / \mathrm{kg}$ & Reference \\
\hline \multicolumn{7}{|c|}{ Obtained by diffusion experiments ${ }^{\text {a }}$} \\
\hline \multicolumn{7}{|l|}{$\rho / \mathrm{g} / \mathrm{cm}^{3}$} \\
\hline 0.953 & MX-80 & $0.1 \mathrm{M} \mathrm{NaClO}_{4}$ & 7 & $1 \times 10^{-6}$ & 92 & $\mathrm{~b}$ \\
\hline 0.996 & MX-80 & $0.1 \mathrm{M} \mathrm{NaClO}_{4}$ & 7 & $1 \times 10^{-6}$ & 51 & $\mathrm{~b}$ \\
\hline 1.6 & mont $^{c}$ & $0.1 ; 0.5 \mathrm{M}^{\mathrm{d}}$ & $8.6-9$ & $6 \times 10^{-5}$ & $1.3 ; 1.6$ & e \\
\hline \multicolumn{7}{|c|}{ Obtained by batch sorption experiments ${ }^{\text {a }}$} \\
\hline \multicolumn{7}{|c|}{$\mathrm{S} / \mathrm{L}$ ratio / g/L f } \\
\hline \multirow[t]{3}{*}{2.5} & MX-80 & 1.3 pore water & 8 & $1 \times 10^{-6}$ & $13 \pm 1.5$ & $\mathrm{~g}$ \\
\hline & & 1.6 pore water & & & $39 \pm 1$ & \\
\hline & & 1.9 pore water & & & $39 \pm 0.9$ & \\
\hline 10 & MX-80 & synthetic ground- & 8.2 & $2.1 \times 10^{-7}$ & 93 & $\mathrm{~h}$ \\
\hline & & water $(0.008 \mathrm{M})$ & & & & \\
\hline $0.32-13.5$ & MX-80 & model pore water & 7.6 & $1 \times 10^{-6}-$ & 28 (average) & $\mathrm{i}$ \\
\hline & & $(0.7 \mathrm{M})$ & & $3 \times 10^{-8}$ & & \\
\hline
\end{tabular}

a If more than one $K_{\mathrm{d}}$ is published in a literature source, the $K_{\mathrm{d}}$ values whose experimental conditions are most similar to the conditions used in the present study are taken.

${ }^{\mathrm{b}}$ Wang et al. (2005)

${ }^{\mathrm{c}}$ mont $=$ montmorillonite

${ }^{\mathrm{d}}$ varying $\mathrm{NaClO}_{4}+1 \times 10^{-2} \mathrm{M}$ CHES buffer $+1 \times 10^{-3} \mathrm{M} \mathrm{C}_{\text {inorg }}+1 \times 10^{-4} \mathrm{M} \mathrm{Ca}^{2+}$

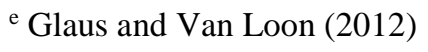

${ }^{\mathrm{f}} \mathrm{S} / \mathrm{L}$ ratio $=$ solid-to-liquid ratio

g Nebelung and Brendler (2009)

${ }^{\text {h }}$ Allard et al. (1982)

${ }^{\mathrm{i}}$ Bradbury and Baeyens (2011)

Table 9 shows a compilation of published $K_{\mathrm{d}}$ values for the $\mathrm{U}(\mathrm{VI})$ sorption to bentonite and montmorillonite obtained by diffusion or sorption experiments. The $K_{\mathrm{d}}$ values from the present 
study differed from the values obtained by Wang et al. (2005) by about one order of magnitude. They worked at a slightly lower $\mathrm{pH}$ and ionic strength compared to the present study, which leads to a different U(VI) speciation and sorption behavior. Under their conditions, $\left(\mathrm{UO}_{2}\right)_{2} \mathrm{CO}_{3}(\mathrm{OH})_{3}{ }^{-}$is most likely the dominant $\mathrm{U}(\mathrm{VI})$ species in solution, which is known to sorb stronger to clay than $\mathrm{Ca}_{2} \mathrm{UO}_{2}\left(\mathrm{CO}_{3}\right)_{3}$ (aq) (Joseph et al., 2013a; Křepelová et al., 2006), thus yielding higher $K_{\mathrm{d}}$ values. In the case of Glaus and Van Loon (2012), besides the $\mathrm{Ca}_{2} \mathrm{UO}_{2}\left(\mathrm{CO}_{3}\right)_{3}(\mathrm{aq})$ complex, a relatively large fraction of various negatively charged uranyl carbonato complexes are present in solution, which, as mentioned before, sorb even less than the $\mathrm{Ca}_{2} \mathrm{UO}_{2}\left(\mathrm{CO}_{3}\right)_{3}(\mathrm{aq})$ complex. Thus, slightly lower $K_{\mathrm{d}}$ values are expected. However, the values differed from the $K_{\mathrm{d}}$ values presented in this study only by a factor of three, which could be regarded as being in good agreement.

Bradbury and Baeyens (2003a) suggest that a comparison between $K_{\mathrm{d}}$ data from intact and dispersed systems is only meaningful when the same water conditions are present. Thus, batch $K_{\mathrm{d}}$ values obtained using the same MX-80 clay, pore waters, and initial U(VI) concentration (Nebelung and Brendler, 2009) provide the best data for comparison with the $K_{\mathrm{d}}$ values obtained by diffusion experiments in this study. The batch $K_{\mathrm{d}}$ values from Nebelung and Brendler (2009) are about one order of magnitude higher than the $K_{\mathrm{d}}$ values determined by diffusion experiments in this study. It could be that more binding sites are accessible to U(VI) in batch sorption experiments, where the clay is dispersed, than in a diffusion experiment, where the clay is compacted. The $K_{\mathrm{d}}$ value may also be affected by the $\mathrm{S} / \mathrm{L}$ ratio as it was described in previous studies for the U(VI) sorption to clay (Joseph et al., 2011) and soils (Zheng et al., 2003). The change in $K_{\mathrm{d}}$ as a function of $\mathrm{S} / \mathrm{L}$ ratio was attributed to the degree of calcium carbonate dissolution in the solid. Zheng et al. (2003) define a formula to calculate the appropriate S/L ratio for sorption experiments with calcareous soils. Applying the same formula to MX-80 resulted in a minimum S/L ratio of $7.5 \mathrm{~g} / \mathrm{L}$. Thus, the low $\mathrm{S} / \mathrm{L}$ ratio used in Nebelung and Brendler (2009) may have led to the discrepancy between their batch $K_{\mathrm{d}}$ values and the $K_{\mathrm{d}}$ values obtained by diffusion experiments in the present study. Allard et al. (1982) and Bradbury and Baeyens (2011) used sufficiently high S/L ratios. However, their batch sorption experiments were conducted with different background electrolytes (ionic strength, composition). Therefore, their results are not directly comparable. 
When fitting the uranium profile in the clay, tortuosities had two orders of magnitude lower values than in the out-diffusion fit. This led to two orders of magnitude lower $D_{\mathrm{e}}$ and $D_{\mathrm{a}}$ values, which means a slower U(VI) in-diffusion than out-diffusion in the investigated system. The

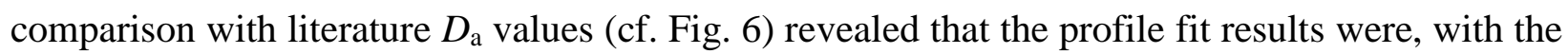
exception of one value reported by Glaus and Van Loon (2012), about two orders of magnitude lower than any reported $D_{\mathrm{a}}$ value for the U(VI) diffusion through MX-80 so far. The outdiffusion fit results agreed quite well with the values that have been reported by Idemitsu et al. (1996) and Glaus and Van Loon (2012).

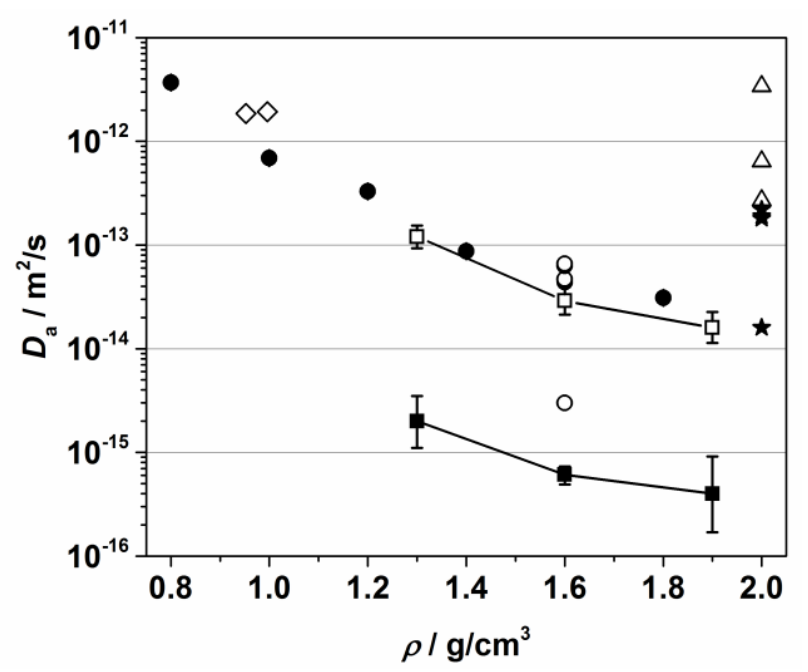

Fig. 6: Comparison of $D_{\mathrm{a}}$ values obtained in this study by fitting of the uranium profiles in the MX-80 (-) and the uranium out-diffusion into the receiving reservoir solutions $(\square)$ with literature values as a function of dry density: $(\Delta)$ Torstenfelt and Allard (1986); (•) Idemitsu et al. (1996); ( $\star$ Ramebäck et al. $\underline{(1998)}$; ( $\diamond$ Wang et al. (2005); (

Idemitsu et al. (1996) investigated the uranium diffusion through two bentonite clays (Kunigel V1, Kunipia F) as a function of dry density at $\mathrm{pH} \mathrm{8-10} \mathrm{in} \mathrm{deionized} \mathrm{water} \mathrm{for} \mathrm{29-}$ 121 days. In Fig. 6 only the diffusion results for Kunipia F are shown because its composition is similar to that of MX-80. Glaus and Van Loon (2012) investigated the diffusion through compacted montmorillonite as a function of ionic strength using ${ }^{233} \mathrm{U}(\mathrm{VI})$ as diffusing tracer. The smallest $D_{\text {a }}$ value is obtained at $I=0.1 \mathrm{M} \mathrm{NaClO}_{4}$ and lies close to the results of the profile fit in the present study. Glaus and Van Loon (2012) interpret the uranium diffusion behavior under their conditions as "anion-like". They observe a change in the profile from a sharp decline with strong tailing to a profile with a smaller decrease without tailing with increasing ionic strength, 
which is characteristic for an increase of $D_{\mathrm{a}}$. The uranium profiles in the present study were influenced by the natural ${ }^{238} \mathrm{U}$ background. Thus, no clear statement concerning a tailing or any "anion-like" diffusion behavior could be made.

Torstenfelt and Allard (1986) studied U(VI) diffusion through MX-80 for 62 days (artificial groundwater, $\mathrm{pH} 8.8-9, I=0.035 \mathrm{M}$ ). They also observe a tailing of the ${ }^{233} \mathrm{U}$ profile at higher diffusion distances. They assume that there are three different $\mathrm{U}(\mathrm{VI})$ fractions or species diffusing through the clay and define a respective $D_{\text {a }}$ value for each species. However, each of their species shows at least a one order of magnitude higher $D_{\mathrm{a}}$ value at $2 \mathrm{~g} / \mathrm{cm}^{3}$ than it was observed in the present study. This difference could be due to a difference in uranium speciation with a larger fraction of anionic U(VI) species in solution or due to the applied diffusion set-up.

Ramebäck et al. (1998) performed a complex long-term diffusion experiment using spent $\mathrm{UO}_{2}$ fuel as uranium source material. Unfortunately, the temperature was not monitored during the experiment. However, they assume that it varied in the range of $(25 \pm 10){ }^{\circ} \mathrm{C}$ (Ramebäck, 2015, personal communication). Their diffusion cells were stopped and the profiles analyzed at different time points. The first $D_{\mathrm{a}}$ value was determined after 3 months of diffusion and lies close to one of the $D_{\mathrm{a}}$ values of Torstenfelt and Allard (1986). The longest time period investigated was 74 months ( six years), similar to the present study. Ramebäck et al. (1998) observed that the $D_{\text {a }}$ values decrease with time by about one order of magnitude (Fig. 6) and conclude that the system at shorter time scales may not be in equilibrium. The large difference in the $D_{\mathrm{a}}$ values of Ramebäck et al. (1998) and the present study could be an effect of the source term $\left(\mathrm{UO}_{2}\right.$ fuel vs. $\mathrm{U}(\mathrm{VI})$ ). Wang et al. (2005) also performed time-dependent diffusion experiments but at time intervals shorter than a year (maximal 85 days). No decrease of the $D_{\text {a }}$ values was observed. This is an additional indication that the change of $D_{\mathrm{a}}$ with time becomes obvious only during longterm experiments.

What causes this retardation of the U(VI) migration within the MX-80? Ramebäck et al. (1998) proposed to consider sorption kinetics with regard to surface redox reactions. On the longer time scale, this leads to surface precipitation of $\mathrm{UO}_{2}$ and thus to an immobilization of the diffusing tracer. Although in this study the diffusion experiments were conducted under aerobic conditions, a redox reaction within the clay core, for instance, with the Fe(II) mineral pyrite (Scott et al., 2007), could not be ruled out and thus was regarded as one possible retardation scenario. However, it could be expected that the reduction of U(VI) to U(IV) would lead to a 
higher apparent $K_{\mathrm{d}}$, which was not observed in the simulations of this study. Thus, reduction of $\mathrm{U}(\mathrm{VI})$ to $\mathrm{U}(\mathrm{IV})$ appeared to be an unlikely explanation for the lower apparent diffusivities observed here.

Xiong et al. (2014) created a meso-scale model to describe species diffusion through porous media and investigated $\mathrm{Ca}_{2} \mathrm{UO}_{2}\left(\mathrm{CO}_{3}\right)_{3}(\mathrm{aq})$ diffusion through bentonite. They obtained similar $D_{\text {a }}$ values as published by Wang et al. (2005). However, they pointed out that the pore space connectivity is dependent on the size and sorption properties of a diffusing species and show that with progression of the diffusion process the pore connectivity decreases due to sorption of the diffusing species onto throat walls. In the long-term, this leads to a decrease of the $D_{\text {a }}$ values. Compared to Wang et al. (2005), one order of magnitude smaller $K_{\mathrm{d}}$ values were obtained in the present study (Tables 9 and 10). Thus, the sorption, and consequently, the blocking of diffusion paths possibly contributed less to the retardation process observed in the present study. The work of Singer et al. (2014) confirmed experimentally the blocking of pores by sorption. At $c_{0}(\mathrm{U}(\mathrm{VI}))=1 \times 10^{-5} \mathrm{M}$, after a particular time point, they observe precipitation of a uraniumbearing phase within silica pores. They assume that the initial diffusion and sorption is thermodynamically controlled by the aqueous U(VI) speciation, but the subsequent precipitation is kinetically controlled by continuous sorption of the respective U(VI) species near the pore openings. This leads to a so-called bottle-neck effect. However, at $c_{0}(\mathrm{U}(\mathrm{VI}))=1 \times 10^{-6} \mathrm{M}$, the U(VI) concentration also used in the present diffusion study, and no precipitation is observed. This would suggest that the formation of a uranium-containing precipitate in the MX- 80 pores was not occurring. The experiment of Singer et al. (2014) was conducted for $336 \mathrm{~h}$ (two weeks). If it is a precipitation reaction with relatively slow kinetics, a blocking of pores would become obvious only in long-term experiments. Thus, the blocking of pores could not be excluded for the $\mathrm{U}(\mathrm{VI})$ diffusion experiments through MX-80.

The present study assumed that the pore water and the MX-80 were in equilibrium. However, long-term mineral alteration processes in the porous medium, leading to changes in porosity, could not be excluded. Keller et al. (2015) investigated the evolution of the interparticle pore space of MX-80 used in a long-term (over two years) part-time heated (about one year) experiment. They observed a formation of a so-called clay-gel or colloidal gel in the interparticle pore space. The clay gel has a similar composition as the surrounding clay but is slightly enriched in $\mathrm{Fe}, \mathrm{Ca}$, and $\mathrm{Si}$. This can be expected since in clay dissolution experiments higher 
silicon than aluminum concentrations are usually measured (Joseph et al., 2013a). Aluminum probably precipitates as hydroxide on the clay surface (Schroth and Sposito, 1997). Sodium montmorillonite, the main component of bentonite, is known to form gels in suspensions with a solid content above 3\% and very low or very high salt concentrations (Abend and Lagaly, 2000). Thereby, colloidal particles coagulate to flocs, which connect in the space. The electrolyte is enclosed within this network. Compared to gels formed in clay suspensions, the clay gel formed in the interparticle space has a higher clay concentration and lack of free water (Keller et al., 2015). Due to the filling of the pore space with clay gel, the interparticle porosity of the clay decreases. Consequently, the pore connectivity decreases substantially. Thus, gas transport through the interparticle pore space is excluded. However, such a change in porosity and pore connectivity may not only be relevant for gas transport, it could also significantly affect the molecular diffusion of slow-migrating tracers like U(VI).

Over time, all scenarios described would hinder or even stop the U(VI) diffusion through MX-80. Thus, they could be responsible or at least contribute to the observed retardation of the U(VI) migration. However, in all cases, the leaching or out-diffusion of natural U(VI) would not be affected.

\subsection{U(VI) diffusion in the context of Archie's and extended Archie's law}

Concerning the evaluation of the diffusion results with Archie's law, Eq. (7) was used to estimate $\varepsilon_{\text {eff }}$ for $\mathrm{U}(\mathrm{VI})$ by inserting the calculated cementation factor of $m=4.7 \pm 1.1$ (Fig. 3), the value for $D_{\mathrm{w}}\left(\mathrm{Ca}_{2} \mathrm{UO}_{2}\left(\mathrm{CO}_{3}\right)_{3}(\mathrm{aq})\right.$ ) (section 2.7), and the modeled $D_{\mathrm{e}}$ values for U(VI) (Table 8). Table 10 compares the results obtained for $\varepsilon_{\text {eff }}$ for the U(VI) in- and out-diffusion. In the case of the U(VI) out-diffusion, about $50 \%$ of the pore space accessible to HTO would be available for $\mathrm{U}(\mathrm{VI})$. It could be assumed that $\mathrm{U}(\mathrm{VI})$ had no access to the clay interlayers, since their contribution to the total porosity varies around 50\% (Appelo, 2013). The estimated values of $\varepsilon_{\text {eff }}$ for the U(VI) in-diffusion are even smaller than for the out-diffusion. Thus, a significant restriction of pore space could be expected. Considering of the uncertainties no significant effect of the dry density on both sets of $\varepsilon_{\text {eff }}$ could be observed. 
Table 10: Estimated values for $\varepsilon_{\mathrm{eff}}(\mathrm{U}(\mathrm{VI}))$ based on Archie's law (error: $\left.2 \sigma\right)$.

\begin{tabular}{lll}
\hline$\rho / \mathbf{g} / \mathbf{c m}^{3}$ & $\varepsilon_{\mathrm{eff}}(\mathbf{U}(\mathbf{V I}))_{\text {in }}$ & $\varepsilon_{\mathrm{eff}}(\mathbf{U}(\mathbf{V I}))_{\text {out }}$ \\
\hline 1.3 & $0.11 \pm 0.11$ & $0.27 \pm 0.16$ \\
1.6 & $0.09 \pm 0.09$ & $0.20 \pm 0.14$ \\
1.9 & $0.07 \pm 0.09$ & $0.16 \pm 0.13$ \\
\hline
\end{tabular}

The definition range of the extended Archie's law, if applied to the U(VI) diffusion, is shown in Fig. 7 using the best-fit values of the empirical factors and $D_{\mathrm{w}}\left(\mathrm{Ca}_{2} \mathrm{UO}_{2}\left(\mathrm{CO}_{3}\right)_{3}(\mathrm{aq})\right)$. If the HTO porosity would also have been accessible to $\mathrm{U}(\mathrm{VI})$, the $D_{\mathrm{e}} / \varepsilon_{\text {eff }}$ relation would lie far outside of the definition range of the extended Archie's law, as depicted by the black filled and open squares in the lower right corner. Using Eq. (8), $\varepsilon_{\text {eff }}$ for U(VI) was estimated. Significantly smaller values were obtained than if the porosity accessible for HTO was assumed. As presented in Fig. 7, the $\varepsilon_{\text {eff }}$ values for the U(VI) out-diffusion ranged from $0.008\left(1.9 \mathrm{~g} / \mathrm{cm}^{3}\right)$ to 0.06 $\left(1.3 \mathrm{~g} / \mathrm{cm}^{3}\right)$. In the case of the $\mathrm{U}(\mathrm{VI})$ in-diffusion, for all three densities $\varepsilon_{\text {eff }}$ values below 0.005 were obtained, i.e., outside of the definition range of the extended Archie's law. In fact, the values were exceptionally low suggesting that there should not be any pore space available for $\mathrm{U}(\mathrm{VI})$ diffusion. This underlines one of the hypotheses discussed above. A significant change in porosity and pore connectivity in the MX-80 during the 6-year diffusion experiment must have occurred.

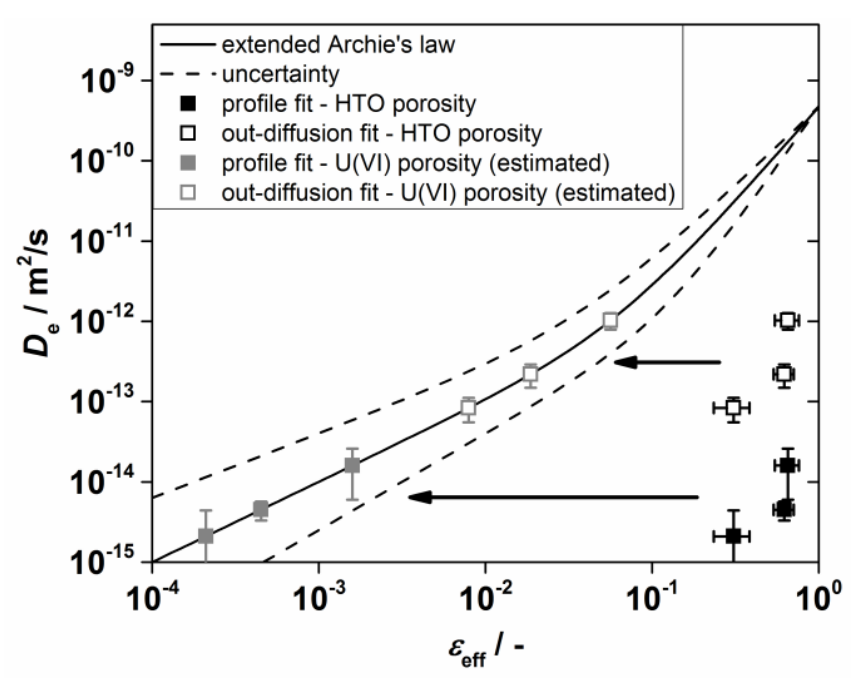

Fig. 7: Relation between $D_{\mathrm{e}}$ and $\varepsilon_{\text {eff }}$ for the U(VI) diffusion in and out of MX-80 bentonite described by extended Archie's law (Van Loon and Mibus, 2015). 


\section{Conclusions}

In this study, laboratory diffusion experiments with compacted MX-80 bentonite were reported with the tracers HTO and U(VI) as a function of clay dry density $\left(1.3,1.6,1.9 \mathrm{~g} / \mathrm{cm}^{3}\right)$. In the case of $\mathrm{U}(\mathrm{VI})$, the experiments were conducted for six years. To approach natural conditions, a complex background electrolyte, synthetic MX-80 pore water, was used as the mobile phase. Speciation calculations showed that under these conditions, $\mathrm{Ca}_{2} \mathrm{UO}_{2}\left(\mathrm{CO}_{3}\right)_{3}(\mathrm{aq})$ would be the dominant U(VI) species in the source reservoir solutions over the entire duration of the experiment.

Within six years, U(VI) diffused about $3 \mathrm{~mm}, 1.5 \mathrm{~mm}$, and $1 \mathrm{~mm}$ deep into the clay at $\rho=$ $1.3,1.6$, and $1.9 \mathrm{~g} / \mathrm{cm}^{3}$, respectively. No through-diffusion of U(VI) was detected. However, a fraction of natural U(VI) leached out of the clay and was detected in the receiving reservoir solutions.

Based on the resulting uranium diffusion depth profiles in the clay and the monitored U(VI) concentration in the receiving reservoir solutions as a function of time, diffusion parameters were obtained for each dry density. The resulting $K_{\mathrm{d}}$ values were very low, which was attributed to the present U(VI) species and their weak sorbing properties. Since the values were in reasonably good agreement with literature data obtained by short-term experiments, no effect of time and only a small effect of dry density on $K_{\mathrm{d}}$ were observed. The $D_{\mathrm{a}}$ values obtained by fitting the diffusion profiles were about two orders of magnitude smaller than the $D_{\mathrm{a}}$ values obtained by fitting the out-diffusion/leaching of U(VI). They were also smaller than any $D_{\text {a }}$ value reported in the literature. Reasons could be (a) reduction of U(VI) to U(IV) followed by precipitation or (b) sorption of U(VI) and consequently, the blocking of pores. Both scenarios were not favored because in contrast to an increased amount of uranium on the clay surface, only low $K_{\mathrm{d}}$ values were determined in this study. Alternatively, (c) a change in clay porosity and pore connectivity caused by the formation of a clay gel in the interparticle space could also explain these observations. This scenario seemed to be the most reasonable. It was supported by the estimation of the diffusion-available pore space using the extended Archie's law. In particular, for the U(VI) in-diffusion, the estimated $\varepsilon_{\text {eff }}$ values were so low that there would not be any U(VI) diffusion possible in the long-term.

In conclusion, these results show that an increase of clay dry density led to a decrease in 
U(VI) migration (by one order of magnitude). Much stronger, however, was the retardation effect on U(VI) diffusion over time (two orders of magnitude). The assumed changes in porosity and pore connectivity may have a significant effect on (1) the migration of uranium and other actinides in compacted clay and in turn, (2) the long-term performance of nuclear waste repositories. 


\section{Acknowledgements}

The manuscript was prepared by LLNL under Contract DE-AC52-07NA27344. This work was supported by the Used Fuel Disposition Campaign of the Department of Energy's Nuclear Energy Program and the U. S. Department of Energy's Office of Biological \& Environmental Research, Subsurface Biogeochemistry Research Program.

The Helmholtz-Zentrum Dresden-Rossendorf thanks the European Commission (Project NF-PRO under contract C2-ST-C-01) for funding the experiment.

The authors would like to thank Dirk Falkenberg for manufacturing the diffusion cells and additives needed for performance of abrasive peeling, Dr. Sina Brockmann for helpful discussions concerning the experimental set-up of the diffusion experiment, Ursula Schaefer, Aline Ritter, Carola Eckardt, and Rachel Lindvall for cation and anion analysis and total organic carbon measurements, Dr. Manja Vogel for plating of the biological contaminants, Carl Steefel from LBNL for helpful advice concerning CrunchFlow modeling, and Peter Rieke from PNNL for support in COMSOL modeling. 


\section{References}

Abend S, Lagaly G. Sol-gel transitions of sodium montmorillonite dispersions. Appl Clay Sci 2000; 16: 201-27.

Allard B, Olofsson U, Torstenfelt B, Kipatsi H, Andersson K. Sorption of actinides in well-defined oxidation states on geologic media. Mater Res Soc Symp Proc 1982; 11: 775-82.

Appelo CAJ. A review of porosity and diffusion in bentonite. Working Report 2013-29. Eurajoki: Posiva Oy 2013.

Appelo CAJ, Van Loon LR, Wersin P. Multicomponent diffusion of a suite of tracers (HTO, Cl, Br, I, Na, $\mathrm{Sr}, \mathrm{Cs}$ ) in a single sample of Opalinus Clay. Geochim Cosmochim Acta 2010; 74: 1201-19.

Bernhard G, Geipel G, Reich T, Brendler V, Amayri S, Nitsche H. Uranyl(VI) carbonate complex formation: Validation of the $\mathrm{Ca}_{2} \mathrm{UO}_{2}\left(\mathrm{CO}_{3}\right)_{3}$ (aq.) species. Radiochim Acta 2001; 89: 511-8.

Bethke CM, Yeakel S. The Geochemist's Workbench®. Urbana, Illinois: Hydrogeology Program, University of Illinois; 2010.

Bleise A, Danesi PR, Burkart W. Properties, use and health effects of depleted uranium (DU): a general overview. J Environ Radioact 2003; 64: 93-112.

Boving TB, Grathwohl P. Tracer diffusion coefficients in sedimentary rocks: correlation to porosity and hydraulic conductivity. J Contam Hydrol 2001; 53: 85-100.

Bradbury MH, Baeyens B. Porewater chemistry in compacted re-saturated MX-80 bentonite: Physicochemical characterisation and geochemical modelling. PSI Report 02-10. Villigen PSI: Paul Scherrer Institute; 2002.

Bradbury MH, Baeyens B. A comparison of apparent diffusion coefficients measured in compacted Kunigel V1 bentonite with those calculated from batch sorption measurements and $D_{\mathrm{e}}(\mathrm{HTO})$ data: a case study for $\mathrm{Cs}(\mathrm{I}), \mathrm{Ni}(\mathrm{II}), \mathrm{Sm}(\mathrm{III}), \mathrm{Am}(\mathrm{III}), \mathrm{Zr}(\mathrm{IV})$ and $\mathrm{Np}(\mathrm{V})$. PSI Report 03-02. Villigen PSI: Paul Scherrer Institute; 2003a.

Bradbury MH, Baeyens B. Porewater chemistry in compacted re-saturated MX-80 bentonite. J Contam Hydrol 2003b; 61: 329-38.

Bradbury MH, Baeyens B. Physico-chemical characterisation data and sorption measurements of Cs, Ni, $\mathrm{Eu}, \mathrm{Th}, \mathrm{U}, \mathrm{Cl}$, I and Se on MX-80 bentonite. Technical Report 09-08. Wettingen: Nagra; 2011.

Brockmann S. Migration of caesium in bentonite: Influence of the pore water composition. Dresden: Hochschule für Technik und Wirtschaft \& Forschungszentrum Rossendorf; 2006.

Bruno J, Arcos D, Cera E, Duro L, Grivé M. Modelling near- and far-field processes in nuclear waste management. In: Grieré R, Stille P, editors. Energy, waste, and the environment: a geochemical perspective. Vol. Special Publications. London: Geological Society; 2004. p. 515-28. 
COMSOL. COMSOL Multiphysics®. Burlington: COMSOL, Inc.; 2014.

Davis JA, Kent DB. Surface complexation modeling in aqueous geochemistry. In: Hochella MF, White AF, editors. Mineral-water interface geochemistry. Reviews in mineralogy. Vol. 23. Min. Soc. Am.; 1990. p. 177-260.

Doherty J. PEST. Model-independent parameter estimation and uncertainty analysis. Brisbane: Watermark Numerical Computing; 2003.

Dong WM, Brooks SC. Determination of the formation constants of ternary complexes of uranyl and carbonate with alkaline earth metals $\left(\mathrm{Mg}^{2+}, \mathrm{Ca}^{2+}, \mathrm{Sr}^{2+}\right.$, and $\left.\mathrm{Ba}^{2+}\right)$ using anion exchange method. Environ Sci Technol 2006; 40: 4689-95.

Fox PM, Davis JA, Zachara JM. The effect of calcium on aqueous uranium(VI) speciation and adsorption to ferrihydrite and quartz. Geochim Cosmochim Acta 2006; 70: 1379-87.

Garcia-Gutierrez M, Cormenzana JL, Missana T, Mingarro M, Alonso U. Analysis of uranium diffusion coefficients in compacted FEBEX bentonite. Mater Res Soc Symp Proc 2004; 807: 603-8.

Glaus MA, Frick S, Rosse R, Van Loon LR. Comparative study of tracer diffusion of HTO, ${ }^{22} \mathrm{Na}^{+}$and ${ }^{36} \mathrm{Cl}^{-}$in compacted kaolinite, illite and montmorillonite. Geochim Cosmochim Acta 2010; 74: 1999-2010.

Glaus MA, Rossé R, Van Loon LR, Yaroshchuk AE. Tracer diffusion in sintered stainless steel filters: measurement of effective diffusion coefficients and implications for diffusion studies with compacted clays. Clays Clay Miner 2008; 56: 677-85.

Glaus MA, Van Loon LR. Diffusive behaviour of charged uranyl complexes in compacted montmorillonite. Clays in Natural \& Engineered Barriers for Radioactive Waste Confinement 5th International Meeting. Montpellier: Andra; 2012, p. 885-6.

Guillaumont R, Fanghänel T, Neck V, Fuger J, Palmer DA, Grenthe I, et al. Update on the Chemical Thermodynamics of Uranium, Neptunium, Plutonium, Americium and Technetium (OECD/NEA, ed.). Amsterdam: Elsevier; 2003.

Herbert H-J, Moog HC. Untersuchungen zur Quellung von Bentoniten in hochsalinaren LösungenAbschlussbericht. GRS-179. Gesellschaft für Anlagen- und Reaktorsicherheit; 2002.

IAEA. Classification of radioactive waste - A safety guide. Safety Series No. 111-G-1.1. Vienna: International Atomic Energy Agency; 1994.

Idemitsu K, Tachi Y, Furuya H, Inagaki Y, Arima T. Diffusion of uranium in compacted bentonites in the reducing condition with corrosion products of iron. Mater Res Soc Symp Proc 1996; 412: 683-90.

Joseph C, Schmeide K, Sachs S, Brendler V, Geipel G, Bernhard G. Sorption of uranium(VI) onto Opalinus Clay in the absence and presence of humic acid in Opalinus Clay pore water. Chem Geol 2011; 284: 240-50. 
Joseph C, Stockmann M, Schmeide K, Sachs S, Brendler V, Bernhard G. Sorption of U(VI) onto Opalinus Clay: Effects of pH and humic acid. Appl Geochem 2013a; 36: 104-17.

Joseph C, Van Loon LR, Jakob A, Steudtner R, Schmeide K, Sachs S, et al. Diffusion of U(VI) in Opalinus Clay: Influence of temperature and humic acid. Geochim Cosmochim Acta 2013b; 109: 74-89.

Keller LM, Holzer L, Gasser P, Erni R, Rossell MD. Intergranular pore space evolution in MX80 bentonite during a long-term experiment. Appl Clay Sci 2015; 104: 150-9.

Keren R, Shainberg I. Water-vapor isotherms and heat of immersion of Na/Ca-montmorillonite systems I: Homoionic clay. Clays Clay Miner 1975; 23: 193-200.

Kerisit S, Liu CX. Molecular simulation of the diffusion of uranyl carbonate species in aqueous solution. Geochim Cosmochim Acta 2010; 74: 4937-52.

Keto P, Gunnarsson D, Johannesson L-E, Hansen J. Assessment of backfilling materials and methods for deposition tunnels. Clays in Natural \& Engineered Barriers for Radioactive Waste Confinement. Vol. 334. Lille: Andra; 2007, p. 31-7.

Kim HT, Suk TW, Park SH, Lee CS. Diffusivities for ions through compacted sodium-bentonite with varying dry bulk density. Waste Manage (N. Y.) 1993; 13: 303-8.

Kozai N, Inada K, Kozaki T, Sato S, Ohashi H, Banba T. Apparent diffusion coefficients and chemical species of neptunium(V) in compacted Na-montmorillonite. J Contam Hydrol 2001; 47: 149-58.

Křepelová A, Sachs S, Bernhard G. Uranium(VI) sorption onto kaolinite in the presence and absence of humic acid. Radiochim Acta 2006; 94: 825-33.

Lee J-Y, Gaona X, Vespa M, Dardenne K, Rothe J, Rabung T, et al. Formation and structural analysis of ternary $\mathrm{Mg}-\mathrm{UO}_{2}-\mathrm{CO}_{3}$ complexes using TRLFS and EXAFS. 15th International Conference on the Chemistry and Migration Behaviour of Actinides and Fission Products in the Geosphere. Santa Fe, New Mexico; 2015, p. 303-4.

Lee JO, Lim JG, Kang IM, Kwon S. Swelling pressures of compacted Ca-bentonite. Eng Geol 2012; 129130: 20-6.

Nebelung C, Brendler V. Uranium(VI) sorption on montmorillonite and bentonite: Prediction and experiments. In: Bernhard G, editor. Annual Report 2008, FZD-511. Dresden: Forschungszentrum Dresden-Rossendorf, Institut für Radiochemie; 2009, p. 45.

OECD/NEA. Physics and safety of transmutation systems - A status report. NEA No. 6090. Paris: OECD; 2006.

OECD/NEA. Considering timescales in the post-closure safety of geological disposal of radioactive waste. NEA No. 6424. Paris: OECD; 2009. 
Payne TE, Brendler V, Comarmond MJ, Nebelung C. Assessment of surface area normalisation for interpreting distribution coefficients $\left(K_{\mathrm{d}}\right)$ for uranium sorption. J Environ Radioact 2011; 102: 888-95.

Ramebäck H, Skålberg M, Eklund UB, Kjellberg L, Werme L. Mobility of U, Np, Pu, Am and Cm from spent nuclear fuel into bentonite clay. Radiochim Acta 1998; 82: 167-71.

Sachs S, Křepelová A, Schmeide K, Koban A, Günther A, Mibus J, et al. Joint Project: Migration of actinides in the system clay, humic substance, aquifer - Migration behavior of actinides (uranium, neptunium) in clays: Characterization and quantification of the influence of humic substances. Wissenschaftlich-Technische Berichte, FZD-460. Dresden: Forschungszentrum DresdenRossendorf; 2007.

Sato H, Ashida T, Kohara Y, Yui M, Sasaki N. Effect of dry density on diffusion of some radionuclides in compacted sodium bentonite. J Nucl Sci Technol 1992; 29: 873-82.

Schroth BK, Sposito G. Surface charge properties of kaolinite. Clays Clay Miner 1997; 45: 85-91.

Scott TB, Tort OR, Allen GC. Aqueous uptake of uranium onto pyrite surfaces; reactivity of fresh versus weathered material. Geochim Cosmochim Acta 2007; 71: 5044-53.

Singer DM, Guo H, Davis JA. U(VI) and Sr(II) batch sorption and diffusion kinetics into mesoporous silica (MCM-41). Chem Geol 2014; 390: 152-63.

Steefel C. CrunchFlow. Software for modeling multicomponent reactive flow and transport. Berkeley, CA: Lawrence Berkeley National Laboratory; 2011.

Stroes-Gascoyne S. Microbiological characteristics of compacted bentonite at a dry density of $1450 \mathrm{~kg} / \mathrm{m}^{3}$ - A literature review. Arbeitsbericht NAB 11-05. Wettingen: Nagra; 2011.

Thoenen T. Speciation calculations supporting the sorption data bases for argillaceous rocks and bentonite for the provisional safety analyses for SGT-E2. Arbeitsbericht NAB 12-52. Wettingen: Nagra; 2014.

Tinnacher RM, Holmboe M, Tournassat C, Bourg IC, Davis JA. Ion adsorption and diffusion in smectite: Molecular, pore, and continuum scale views. Geochim Cosmochim Acta 2016; 177: 130-49.

Torstenfelt B, Allard B. Migration of fission products and actinides in compacted bentonite. SKB Technical Report 86-14. Stockholm: Swedish nuclear fuel and waste management CO; 1986.

Trepte P. Diffusion of tritiated water (HTO) through compacted bentonite samples: Effect of sample thickness. Dresden: Hochschule für Technik und Wirtschaft Dresden \& Forschungszentrum Rossendorf; 2004.

Van Loon LR, Baeyens B, Glaus MA, Bradbury MH, Müller W, Schaible A. NF-PRO Report, Contract Number: FI6W-CT-2003-02389, RTD Component: 2, Work Package: 2.5. Deliverable (D-N ${ }^{\circ}$ : 
2.5.20), Reporting period: 01/01/04 - 31/12/07. European Commission - Community Research; 2007a.

Van Loon LR, Eikenberg J. A high-resolution abrasive method for determining diffusion profiles of sorbing radionuclides in dense argillaceous rocks. Appl Radiat Isot 2005; 63: 11-21.

Van Loon LR, Glaus MA, Müller W. Anion exclusion effects in compacted bentonites: Towards a better understanding of anion diffusion. Appl Geochem 2007b; 22: 2536-52.

Van Loon LR, Mibus J. A modified version of Archie's law to estimate effective diffusion coefficients of radionuclides in argillaceous rocks and its application in safety analysis studies. Appl Geochem 2015; 59: 85-94.

Van Loon LR, Soler JM. Diffusion of HTO, ${ }^{36} \mathrm{Cl}^{-},{ }^{125} \mathrm{I}^{-}$, and ${ }^{22} \mathrm{Na}^{+}$in Opalinus Clay: Effect of Confining Pressure, Sample Orientation, Sample Depth and Temperature. PSI Report 04-03. Villigen PSI: Paul Scherrer Institute; 2004.

Van Loon LR, Soler JM, Jakob A, Bradbury MH. Effect of confining pressure on the diffusion of HTO, ${ }^{36} \mathrm{Cl}^{-}$and ${ }^{125} \mathrm{I}^{-}$in a layered argillaceous rock (Opalinus Clay): diffusion perpendicular to the fabric. Appl Geochem 2003; 18: 1653-62.

Volkmer M. Kernenergie - Basiswissen. Berlin: Informationskreis KernEnergie; 2007.

Wang XK, Chen CL, Zhou X, Tan XL, Hu WP. Diffusion and sorption of U(VI) in compacted bentonite studied by a capillary method. Radiochim Acta 2005; 93: 273-8.

Wu T, Amayri S, Drebert J, Van Loon LR, Reich T. Neptunium(V) sorption and diffusion in Opalinus Clay. Environ Sci Technol 2009; 43: 6567-71.

Wu T, Dai W, Xiao GP, Shu FJ, Yao J, Li JY. Influence of dry density on HTO diffusion in GMZ bentonite. J Radioanal Nucl Chem 2012; 292: 853-7.

Xiong Q, Jivkov AP, Yates JR. Discrete modelling of contaminant diffusion in porous media with sorption. Microporous Mesoporous Mater 2014; 185: 51-60.

Zheng ZP, Tokunaga TK, Wan JM. Influence of calcium carbonate on U(VI) sorption to soils. Environ Sci Technol 2003; 37: 5603-8. 


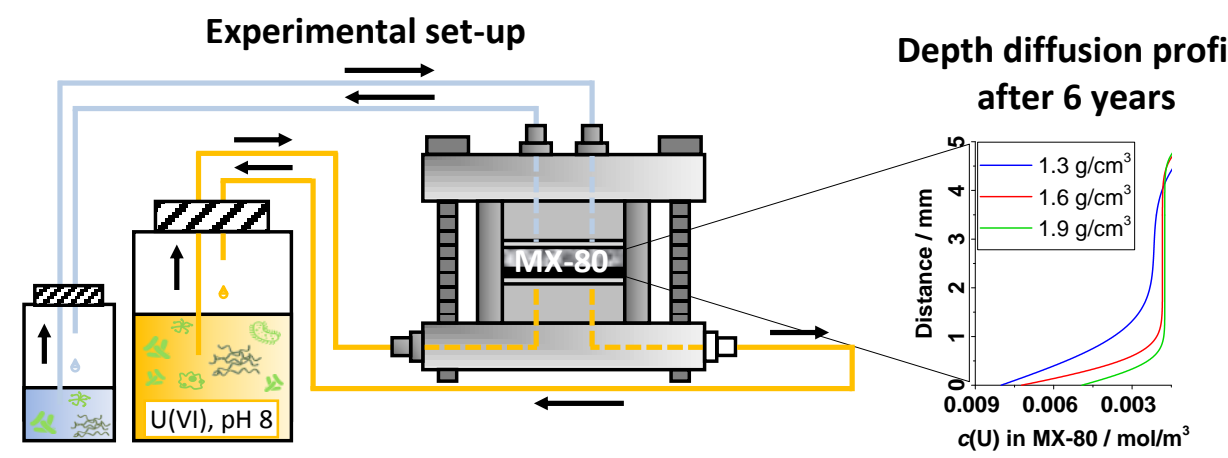

